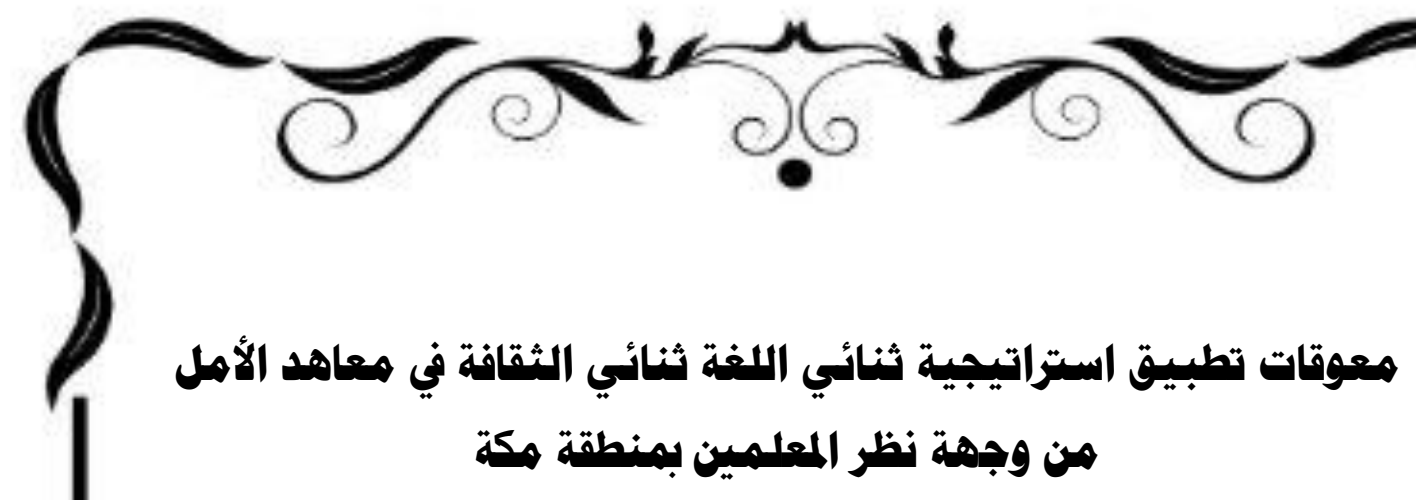

Obstacles of bilingual bicultural strategy's application in AlAmal Institute for the deaf teachers' viewpoint in Makkah Province

$$
\text { إlul }
$$

ضيه بنت عبدالرحمن بن علي النفيعيى

Dai Abdulrahman Ali Al-Nafi'i

باحثة بقسم التربية الخاصة بجامعة جدة

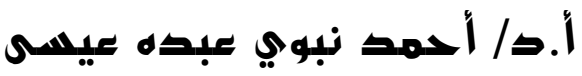

Prof. Ahmed Nabawi Abdo Issa

أستاذ بقسم التربية الخاصة بجامعة جدة

Doi: 10.21608/jasht.2022.212154

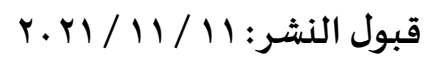

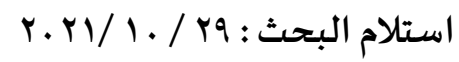

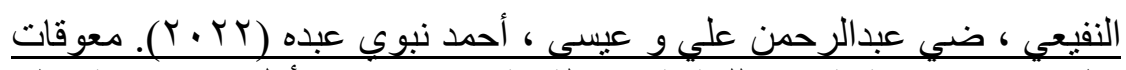

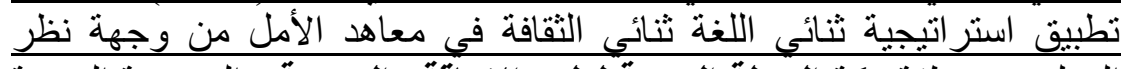

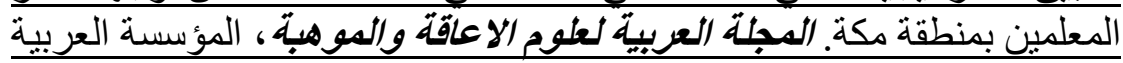

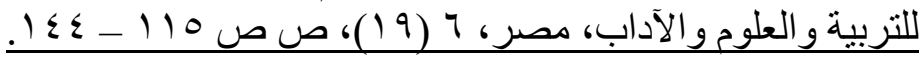




\section{معوقات تطبيق استراتيجية ثنائي اللغة ثنائي الثقافة في معاهد الأمل من وجهة نظر المعلمين بمنطقة مكة اللمة}

هدفت الدراسة إلى التعرف على واقع معرفة واستخدام استراتيجية ثنائي اللغة ثنائي

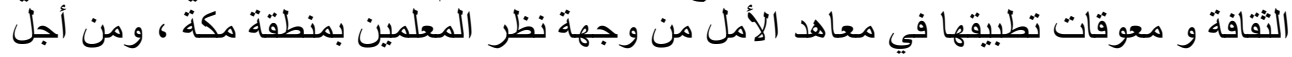

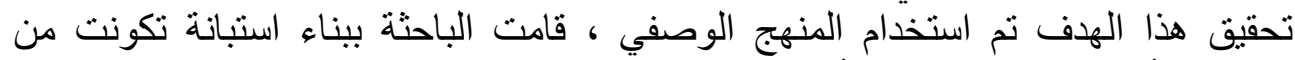

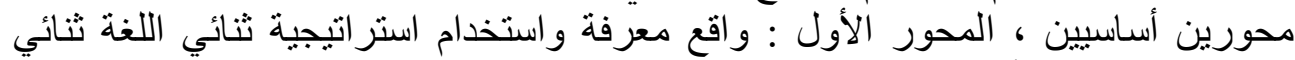

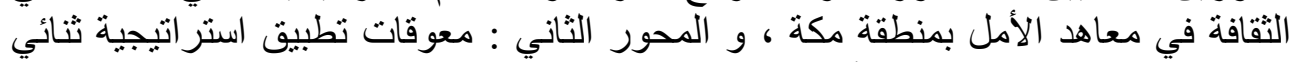

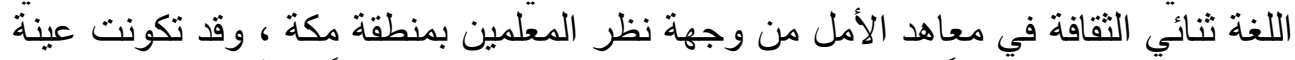

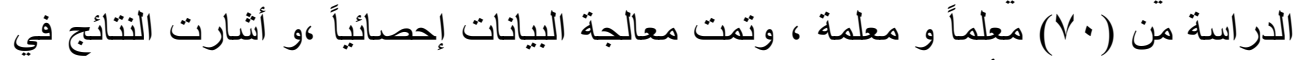

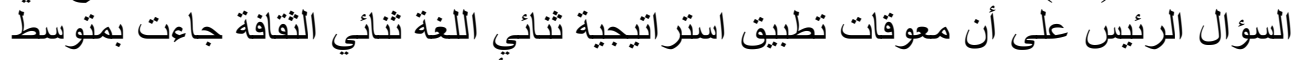

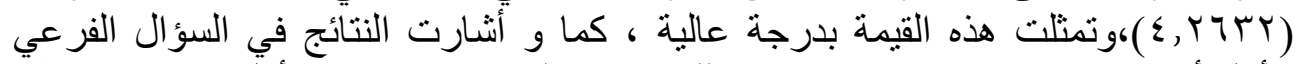

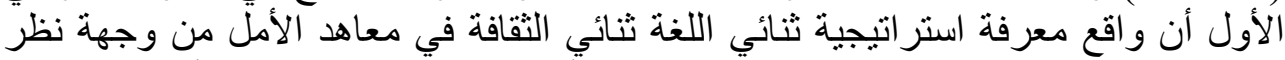

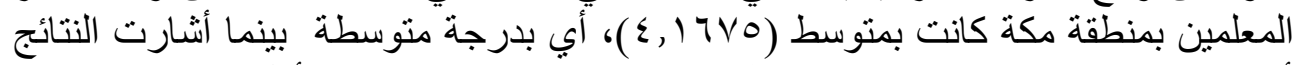

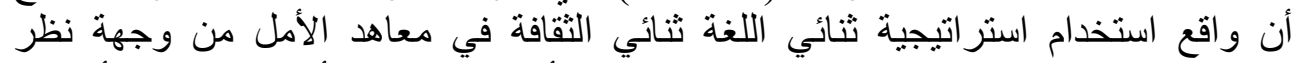

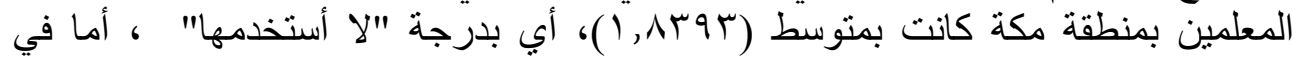

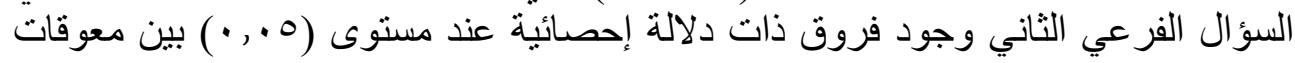

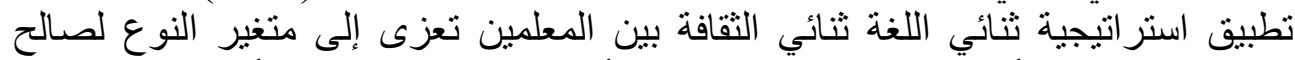

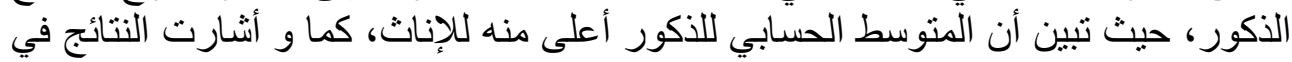

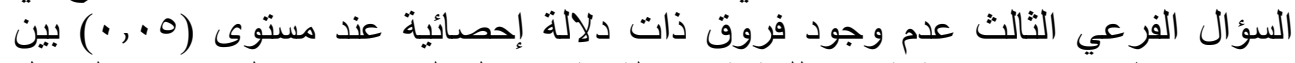

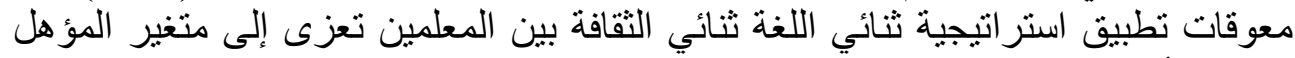

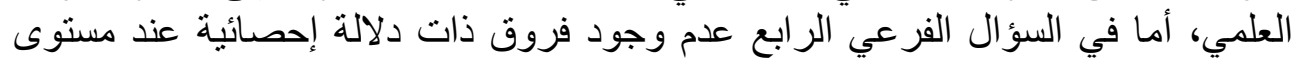

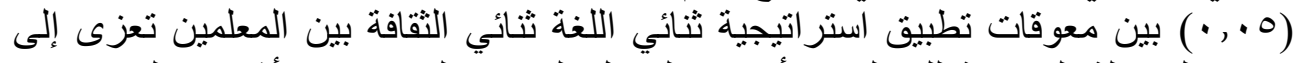

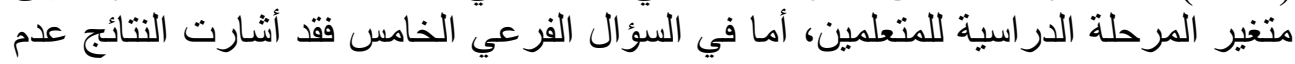

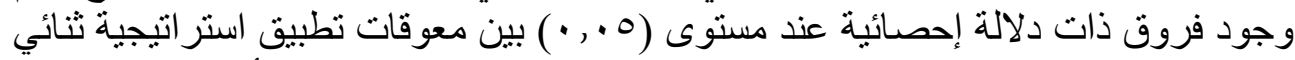

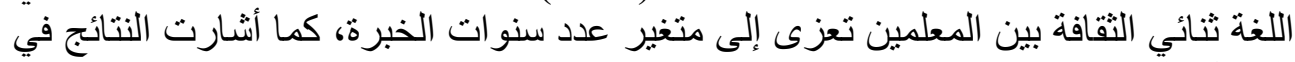

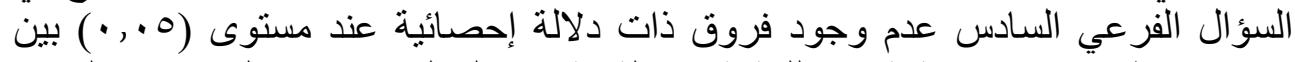

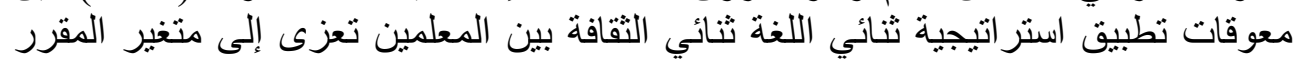

\section{Abstract:}

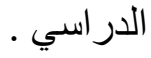

The study aimed to identify the reality of knowing and using a bilingual, bicultural strategy and the obstacles to its application in Al- 
Amal institutes from the teachers' point of view in the Makkah Province, In order to achieve this goal The descriptive approach was used , A questionnaire developed It consisted of two main axes, The first axis: the reality of using the bilingual bicultural strategy in AlAmal institutes in the Makkah Province, And the second axis: Obstacles of bilingual bicultural strategy's application in Al-Amal Institute for the deaf teachers' viewpoint in Makkah Province, The study Sample and Population involved (70) Teachers, and The data was processed statistically. The results indicated in the main question that the Obstacles of bilingual bicultural strategy's application in AlAmal Institute for the deaf came at an average of (4.2632), and this value was largely represented, The results indicated in the first subquestion that the reality of knowing the bilingual, bilingual, bilingual strategy in Al-Amal Institutes in the Makkah Province was at an average of (4.1675), that is at a medium degree While the results indicated that the reality of using the bilingual biculture strategy in AlAmal institutes from the teachers' point of view in the Makkah province was at an average of (1.8393) the degree of "I do not use it", As for the second sub-question, there are statistically significant differences at the level (0.05) between the Obstacles of bilingual bicultural strategy's application among teachers due to the gender variable in favor of males, the results also indicated in the third subquestion that there were no statistically significant differences at the level (0.05) due to the educational qualification variable, As for the fourth sub-question, there are no statistically significant differences at the level (0.05) due to the variable of the academic stage of the learners, As for the fifth sub-question, the results indicated that there were no statistically significant differences at the level (0.05) due to the variable number of years of experience, The results in the sixth sub-question also indicated that there were no statistically significant differences at the level (0.05) school subject variable. 
إن أحد معايير تقدم الأمم ورقيها هو درجة اهتمامها بالأفر اد من ذوي الاحتياجات

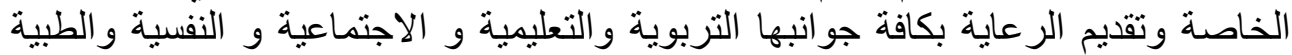

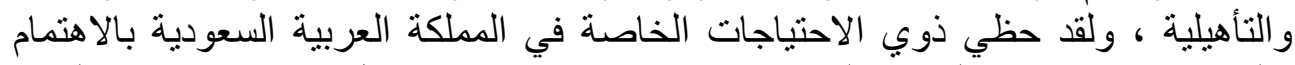

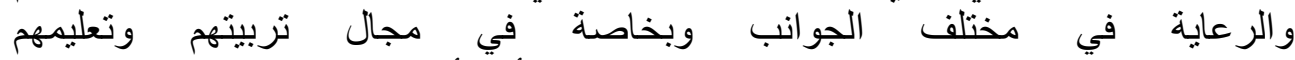

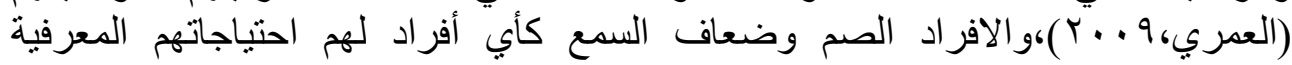

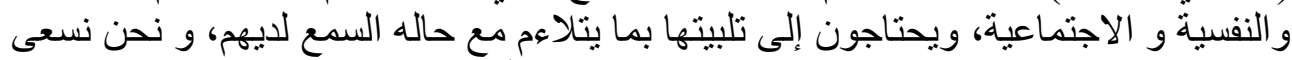

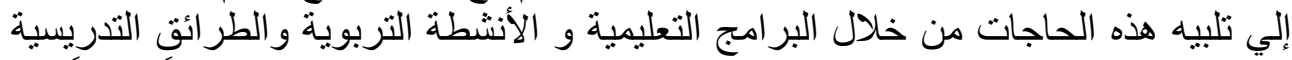

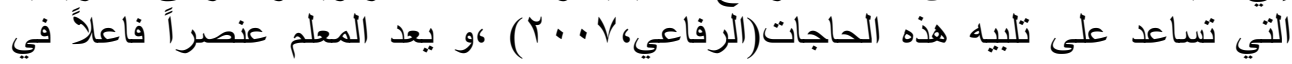

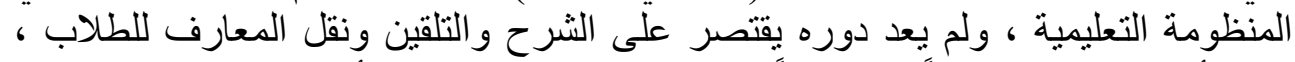

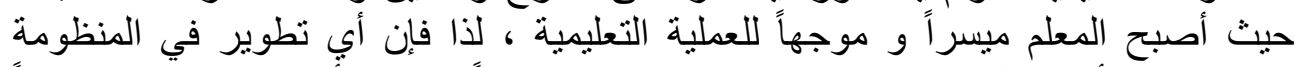

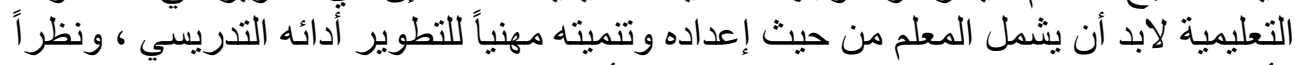

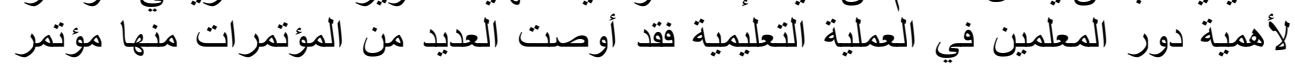

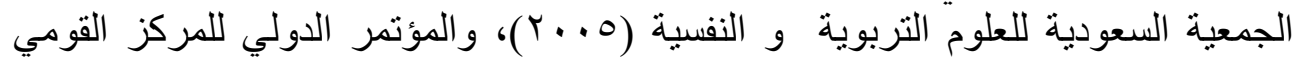

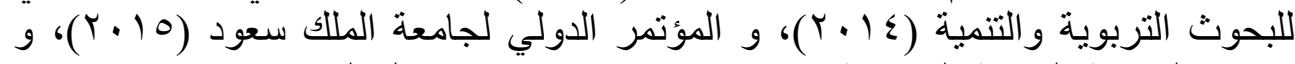

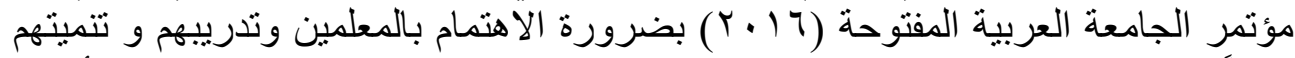

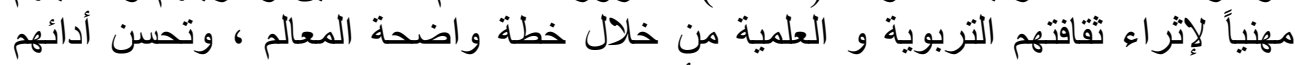

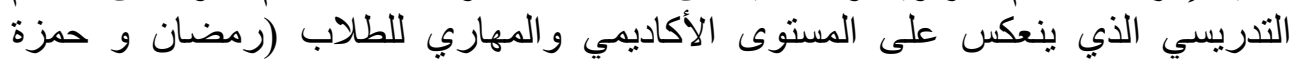
. ( 1 . .

واستراتيجية ثنائي التقافة ثنائي اللغة من الاستراتيجيات الفاعلة التي تعزز أداء

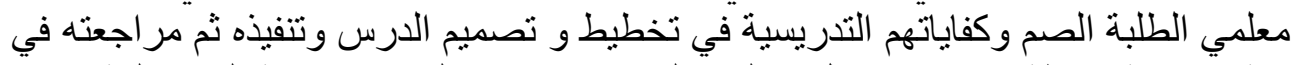

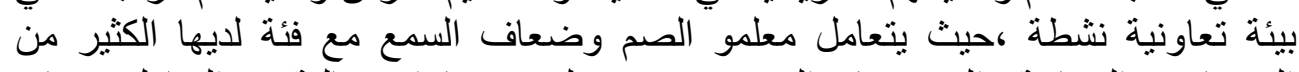

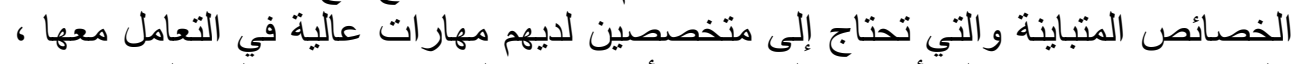

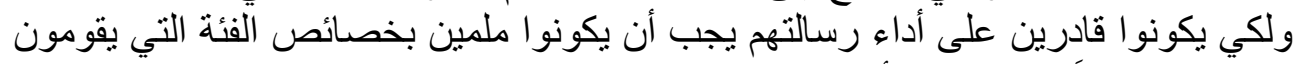

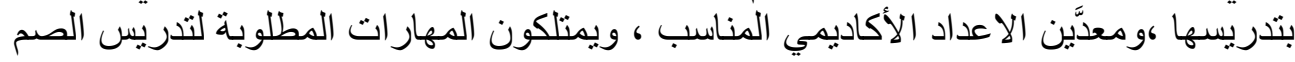

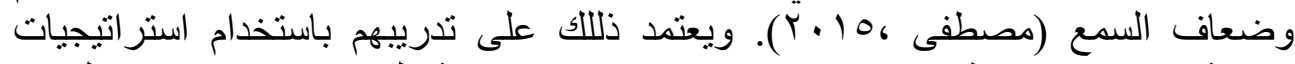

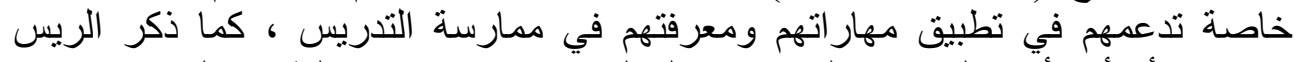

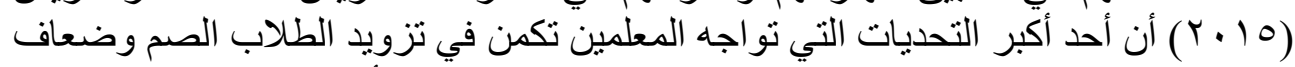

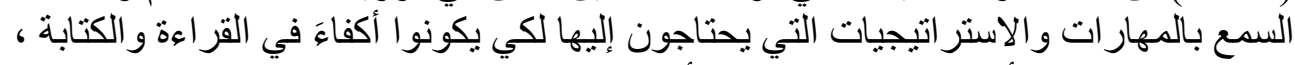

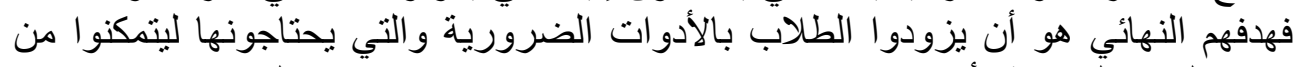

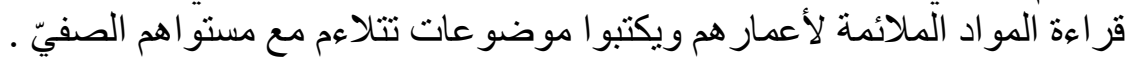




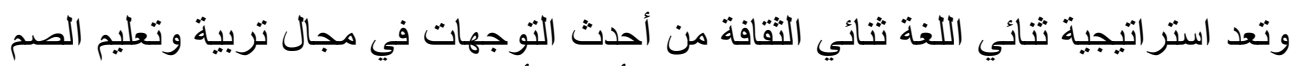

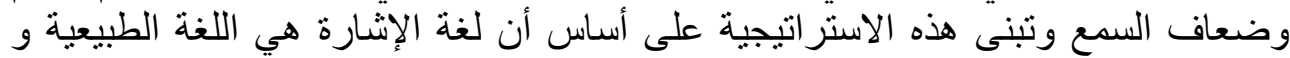

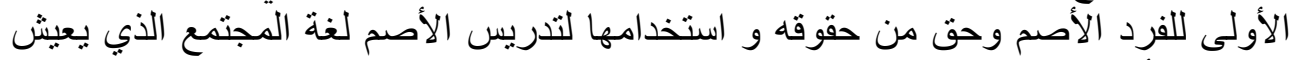

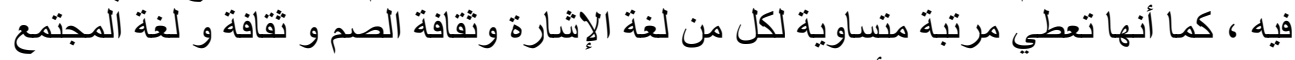

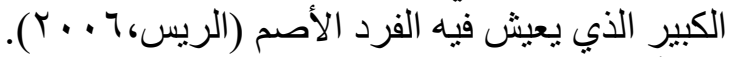

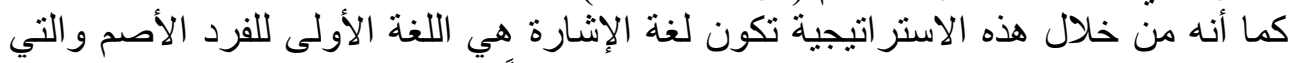

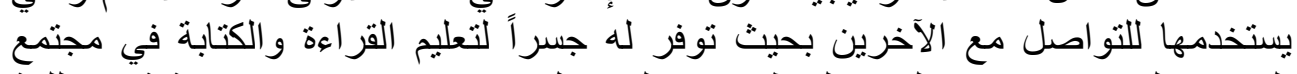

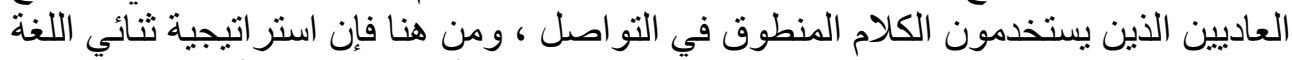

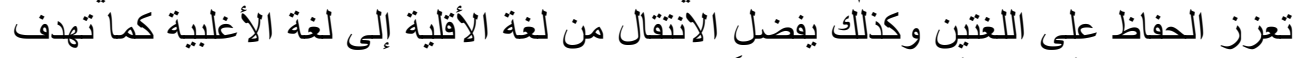

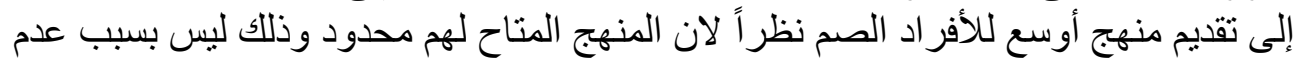

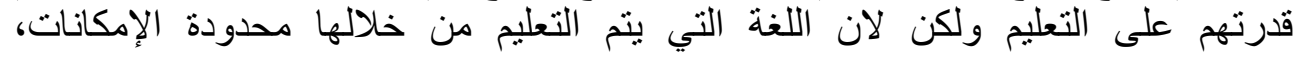

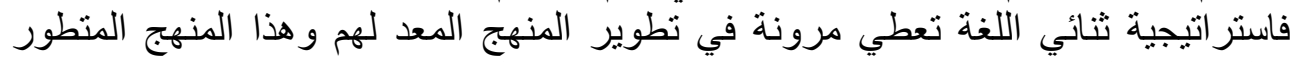

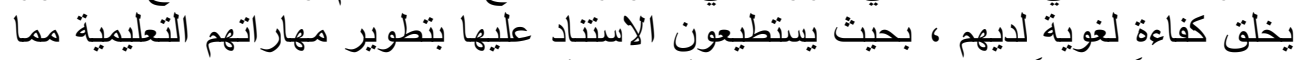

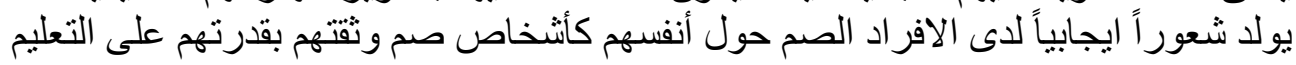

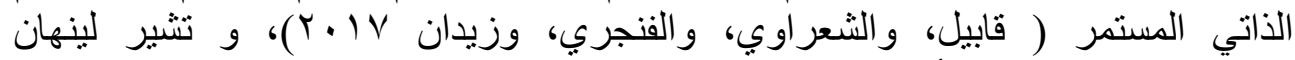
(Lenihan,2010)

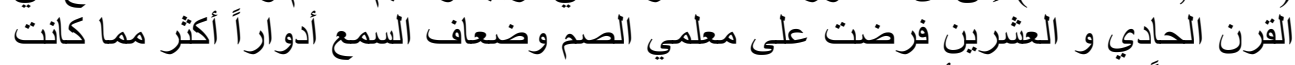

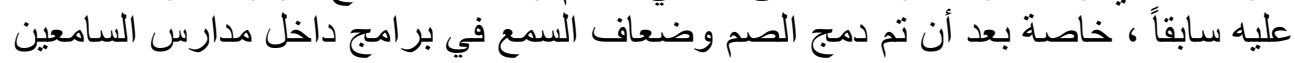

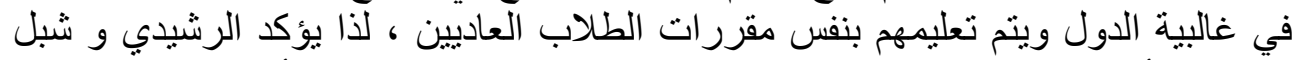

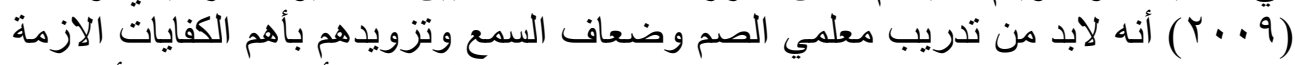

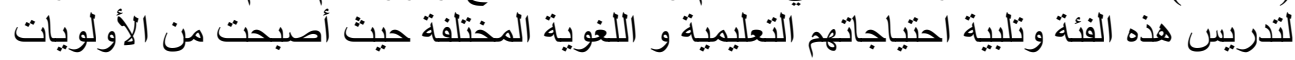

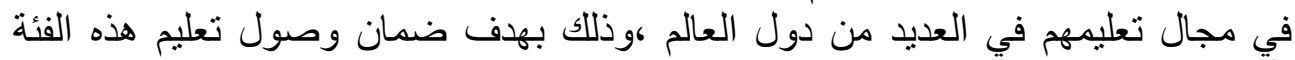
مشكلة الأعلى مستو ياته

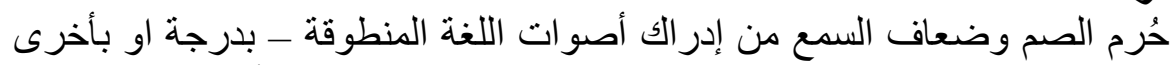

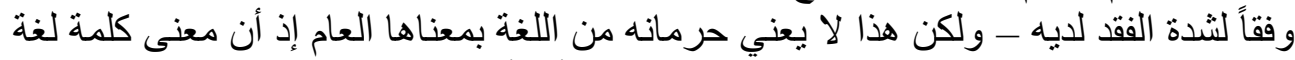

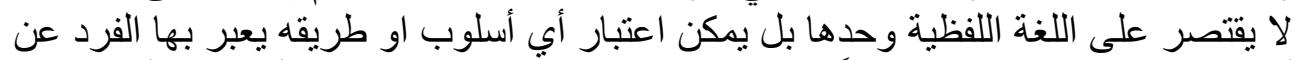

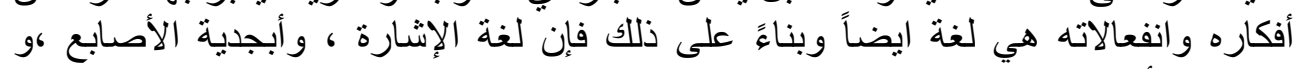

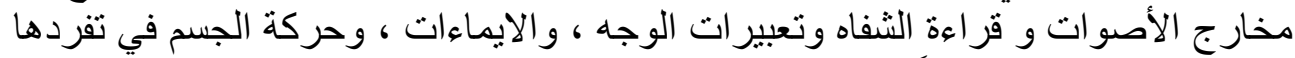

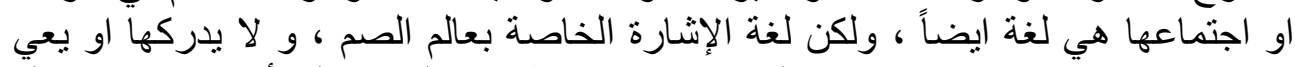

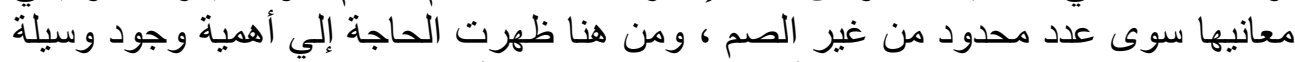
للاتصال المباثر بين الصم وباقي أفراد المجتمع ، حيث أن الصم يحتاجون في حياتهم إلى الى الى 
لغتين ، لغة غير لفظية وهي ( لغة الإشارة ) يعيشون بها في مجتمع الصم ، و اللغة المنطوقة

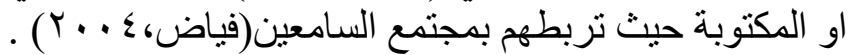

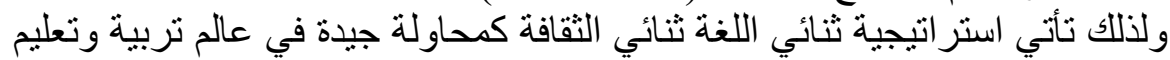

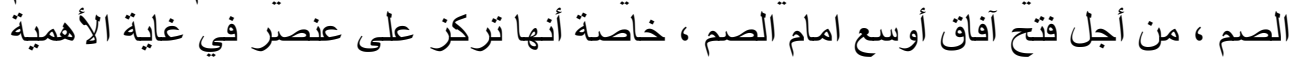

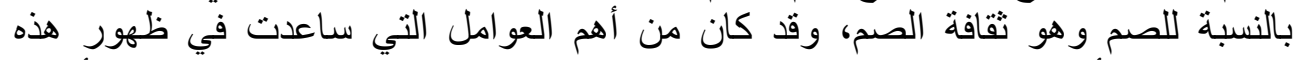

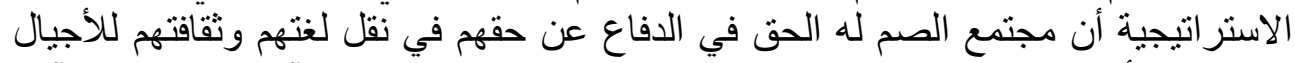

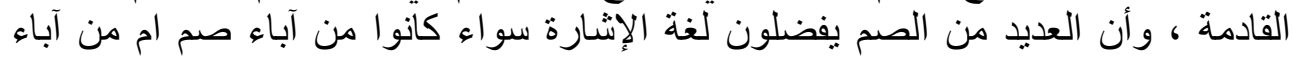

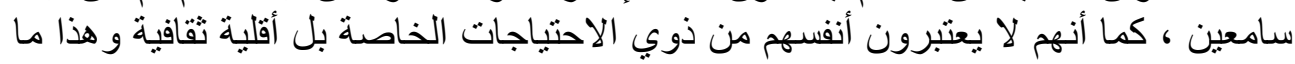

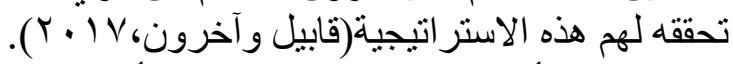

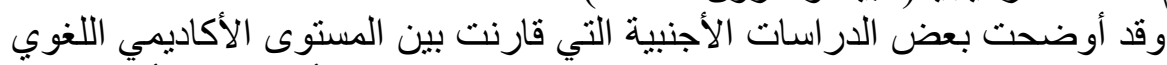

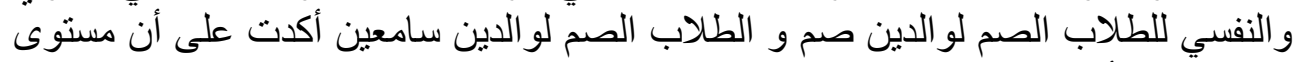

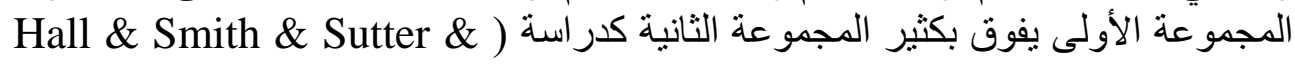
Hermans \& Knoors \& Ormel \& ) و در ع (DeWindt \& Dye , 2018

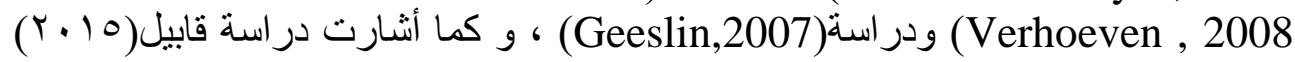

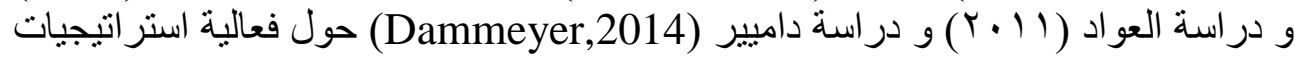

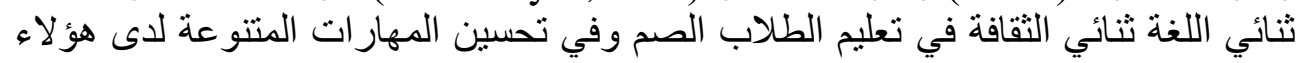

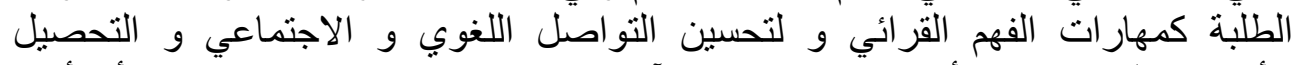

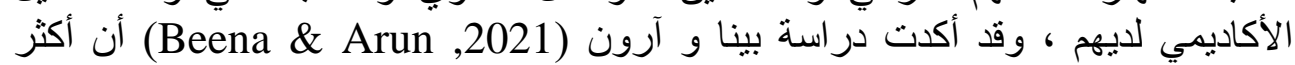

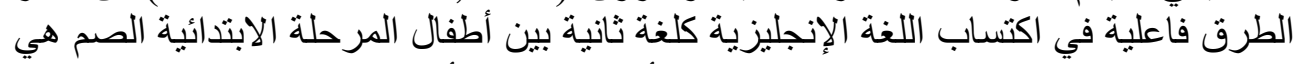

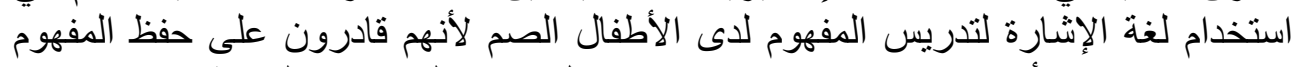

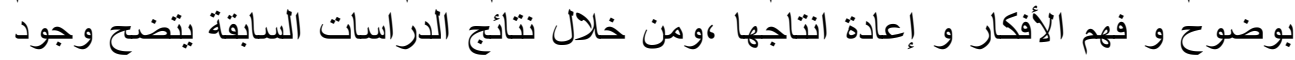

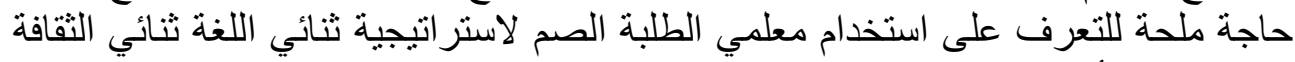

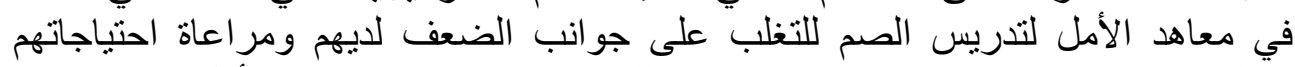

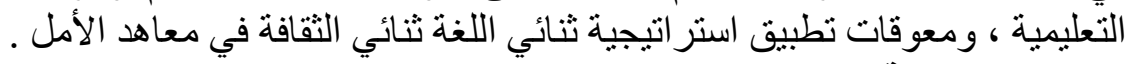
تساؤلات الدراسة ومعة

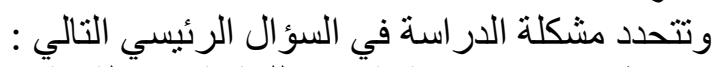

ما معوقات تطبيق استراتيجية ثنائي اللغة ثنائي الثنافئة الثئية في معاهد الأمل من وجهة نظر

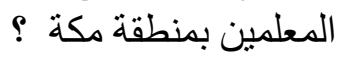
ويتطلب هذا السؤ ال الإجابة على الأسئلة الفر عية الآتية :

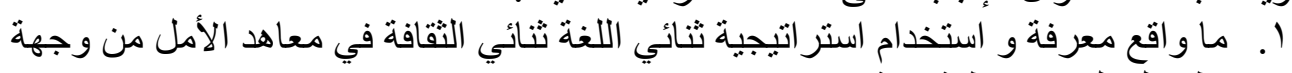
نظر المعلمين بمنطقة مكة ؟ 


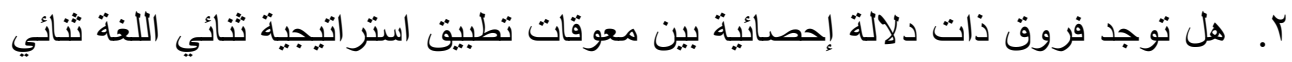

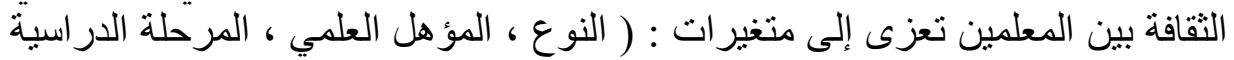

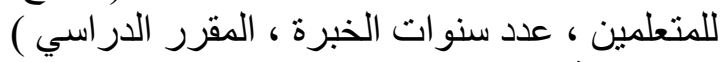
أهداف الدراسة الدينة

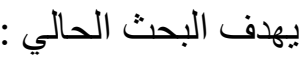
1. التعرف إلى و أقع استخدام استر اتيجية ثنائي اللغة ثنائي التقافة في معاهد الأمل بمنطقة مكة. r. . تحديد معوقات تطبيق استر اتيجية ثنائي اللغة ثنائي الثقافة في معاهد الأمل بمنطقة مكة . أهمية الدراسة تالتضح أهمية البحث في التالي : التئي ا.التعرف إلى واقع أستخدام استر اتيجية ثنائي اللغة ثنائي الثقافة ومدى معرفة و إلمام

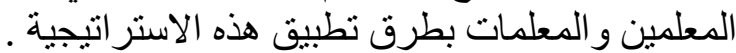

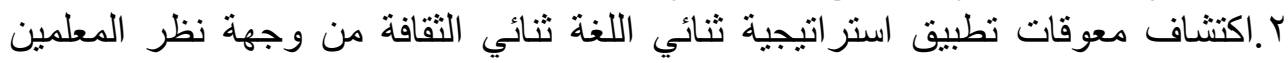

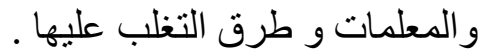

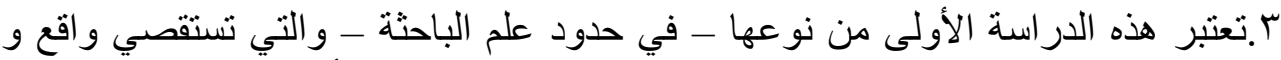
معوقات تطبيق استر اتيجية ثنائي اللغة ثنائي النقافة في معاهد الأمل في المملكة العربية

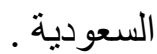

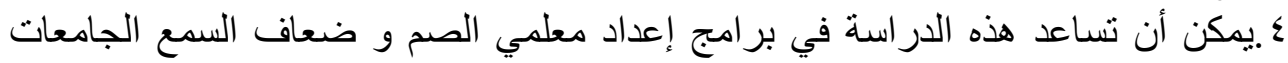

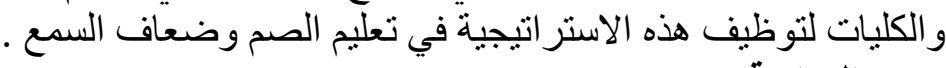
حدود الدراسة

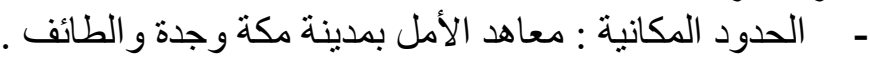

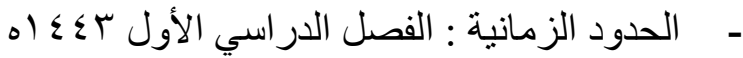

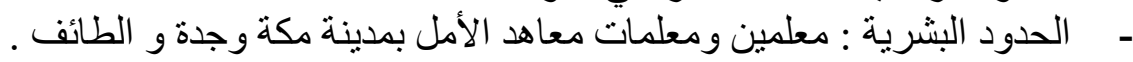
مصطات الار استة

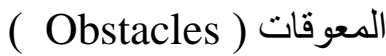

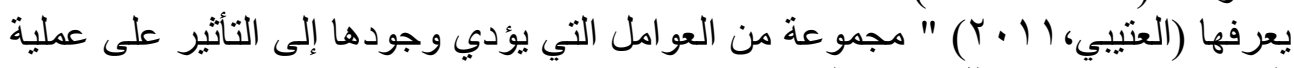

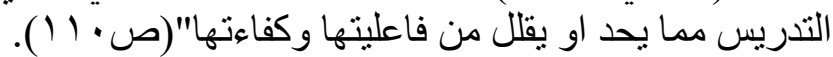

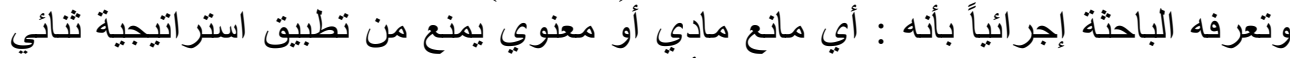

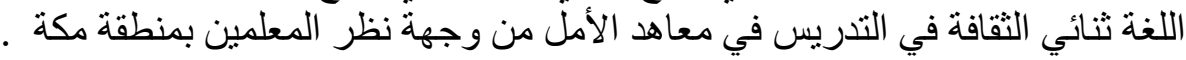

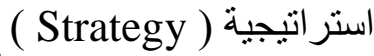

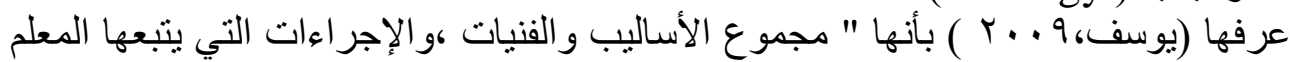

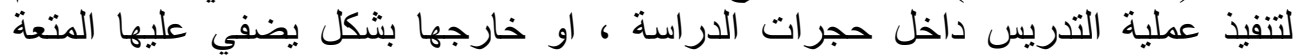


والتشويق ويحقت أقصى قدر من الأهداف التعليمية بأقل قدر جهد ، وفي أقل وقت ممكن "(ص

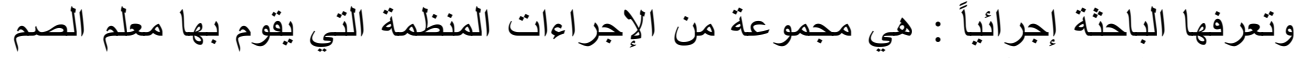

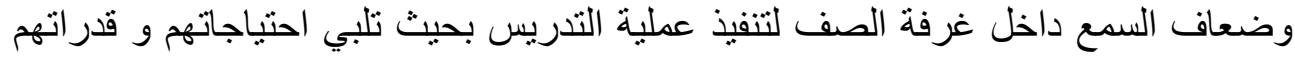
الخاصة .

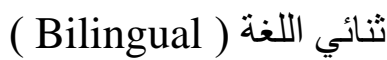

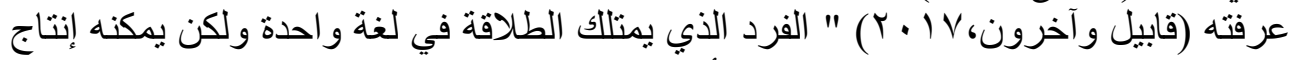

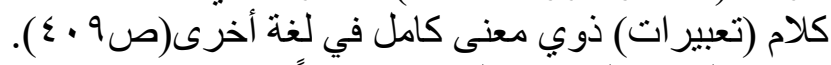

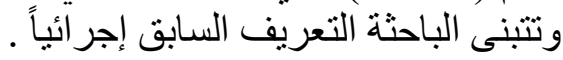

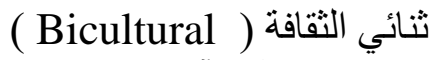

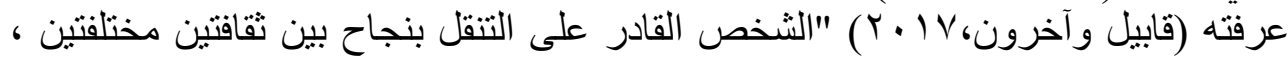

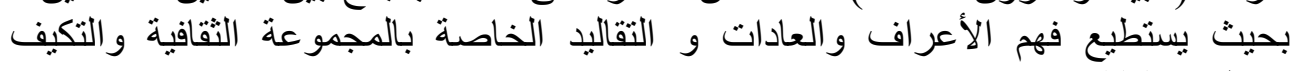

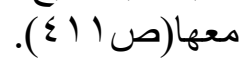
وتتبنى الباحثة التعريف السابق إجر ائياً.

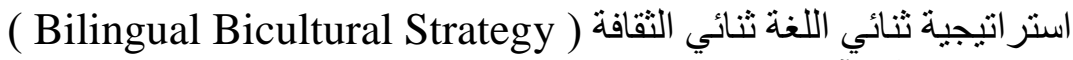

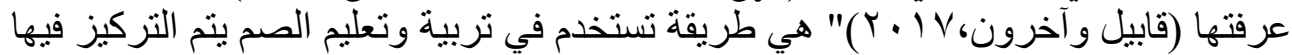

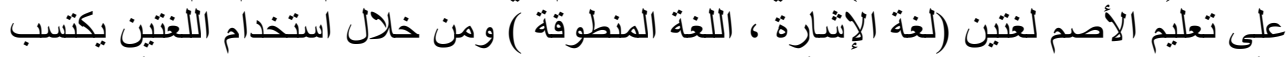

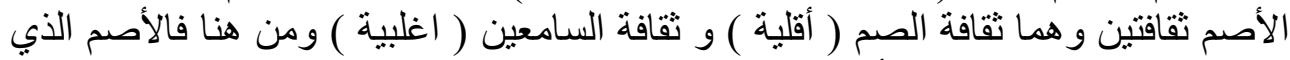

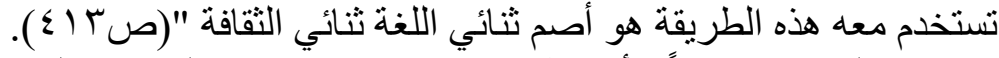

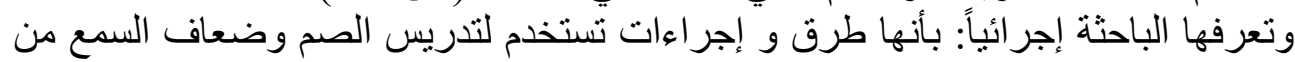

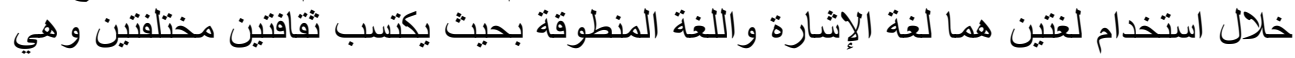

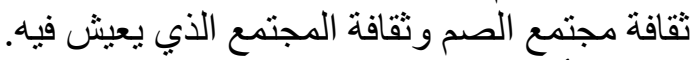

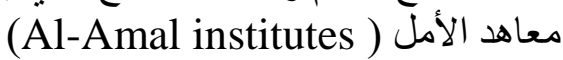

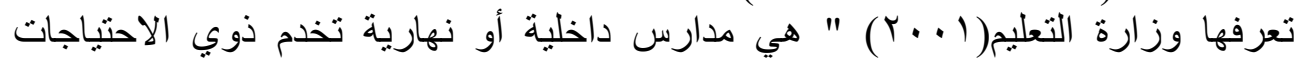

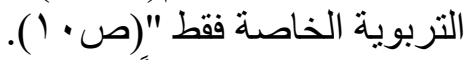

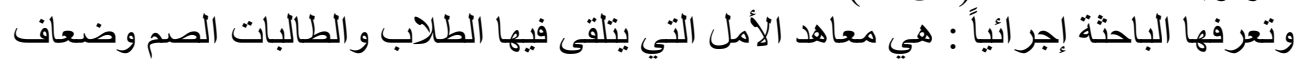

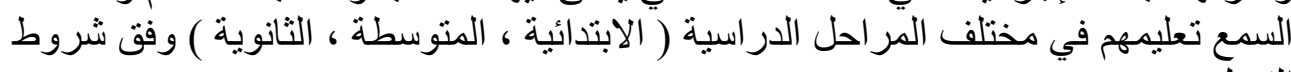
القبول.

الإطار النظري والأدب التربوي السابث

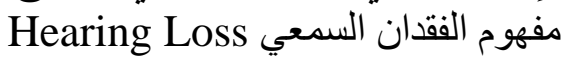




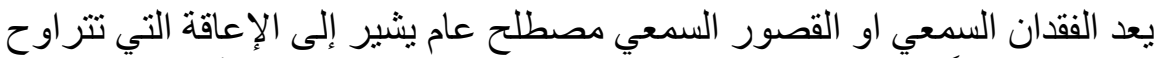

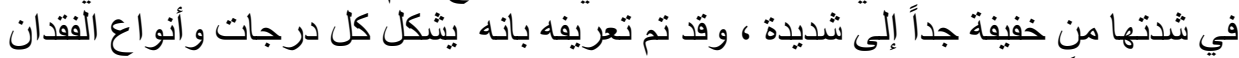

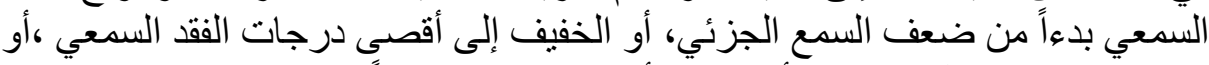

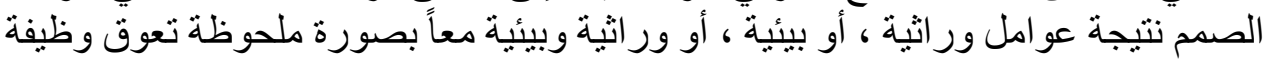

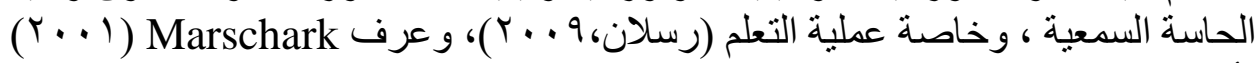

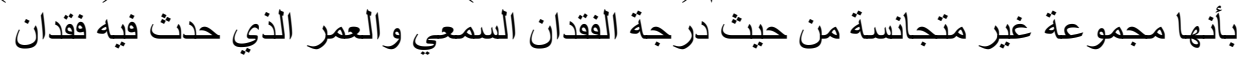
وبهذا يمكن التمييز بين طائفتين من الفقدان السمعي و هما :

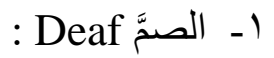

عرف Moores الصمم ( Moores,2001, المشار إليه في Geeslin,2007) أنه مقدار

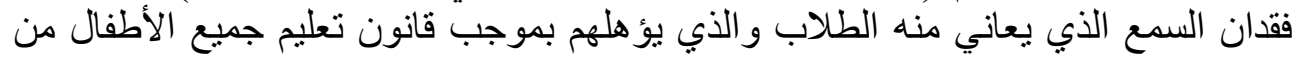

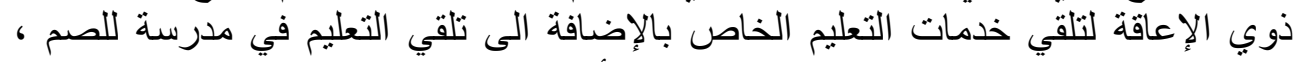

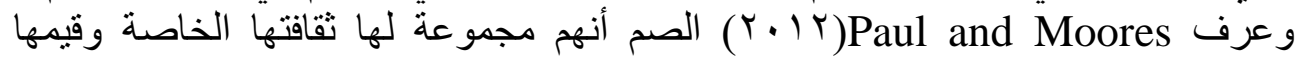

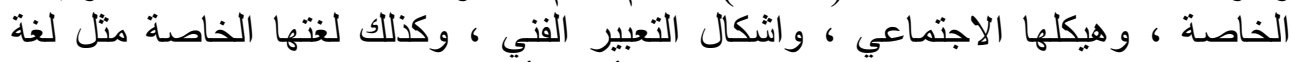

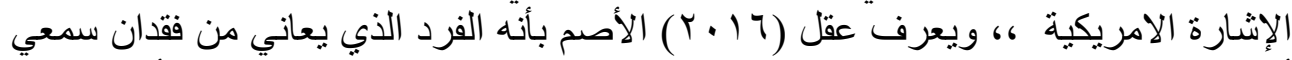

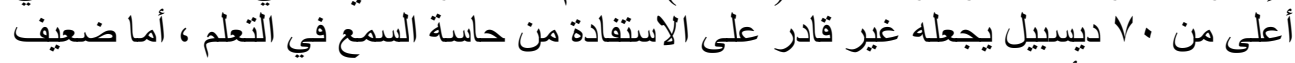

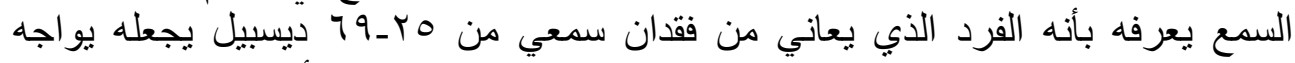

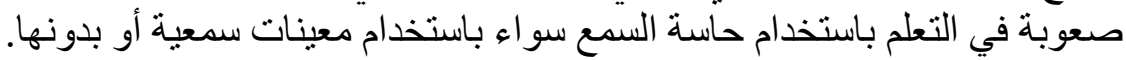

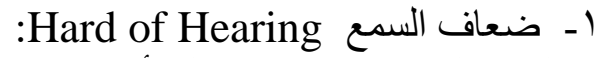

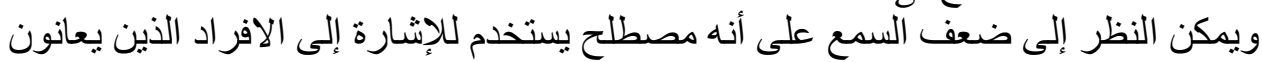

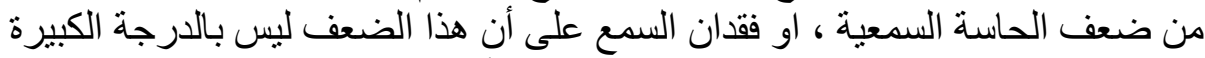

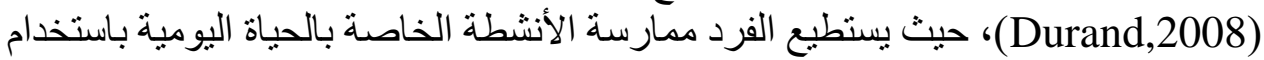

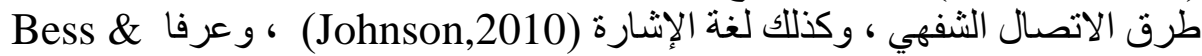

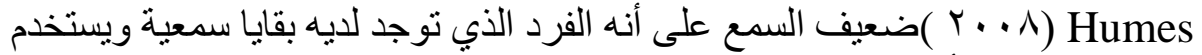

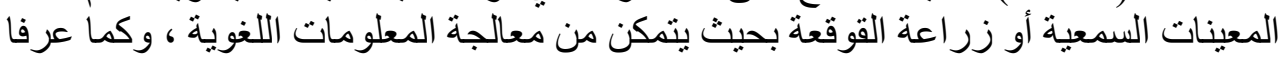
Hallahn \& Kuffman

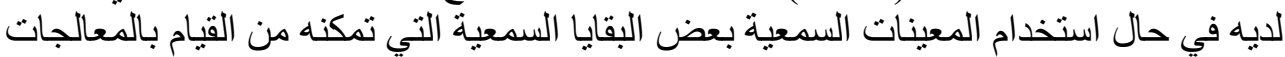

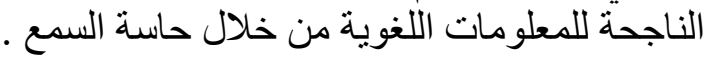

ثنائي اللغة ثنائي الثقافة ( Bilingual Bicultural) 
تعد ثنائي اللغة ثنائي الثقافة من أحدث التوجهات العالمية في مجال تربية وتعليم

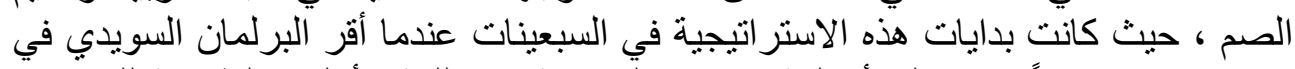

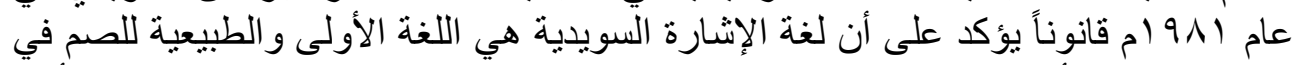

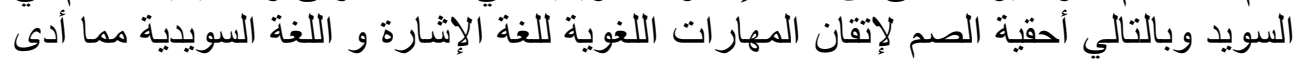

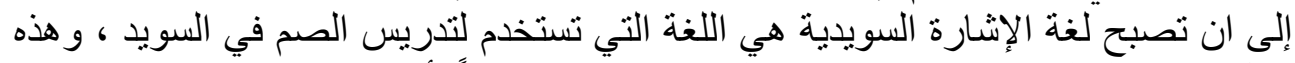

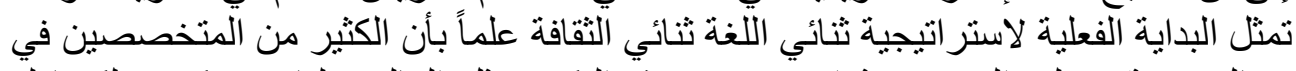

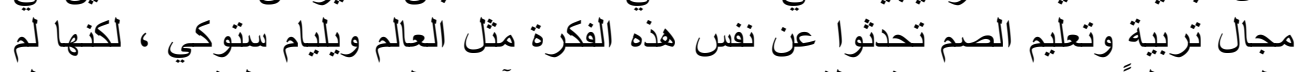

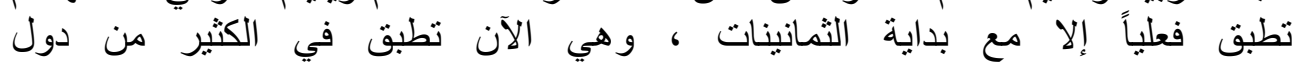

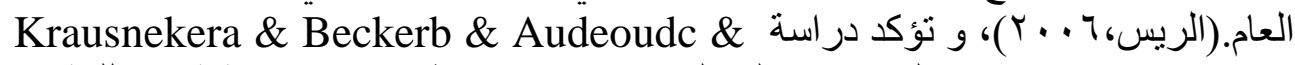

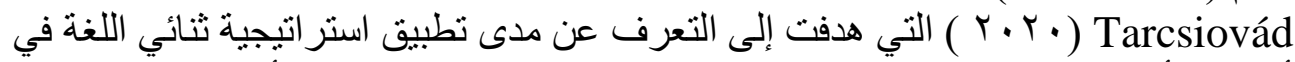

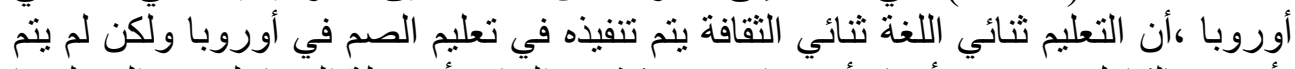

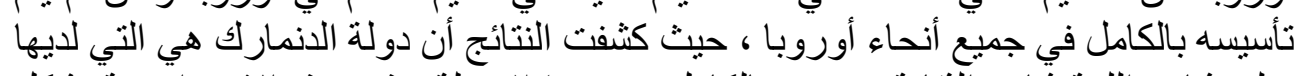

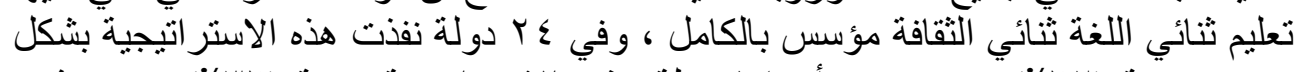

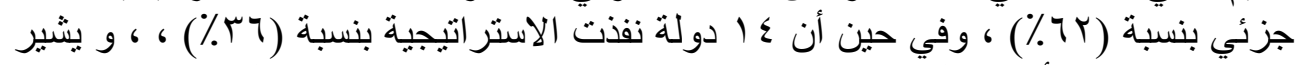

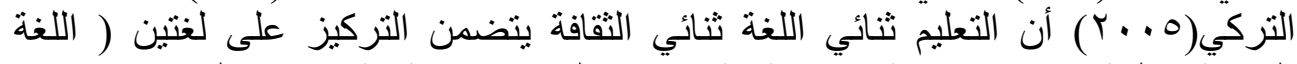

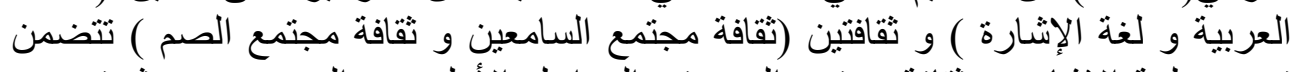

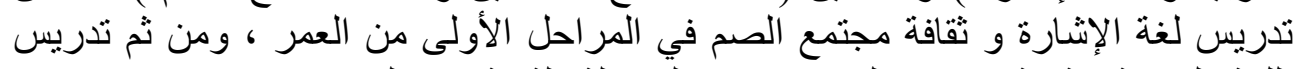

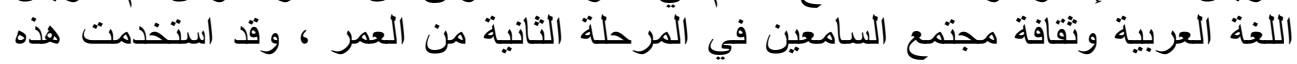

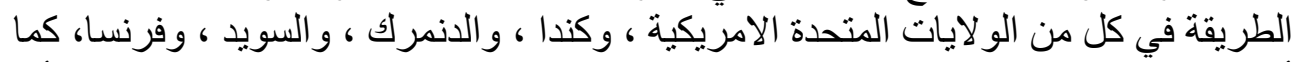

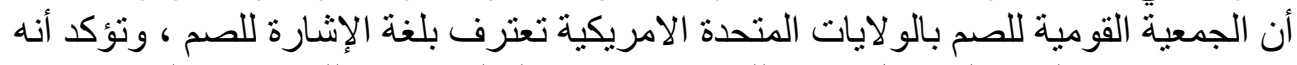

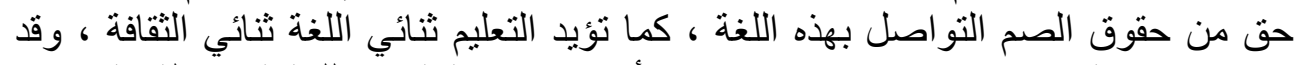

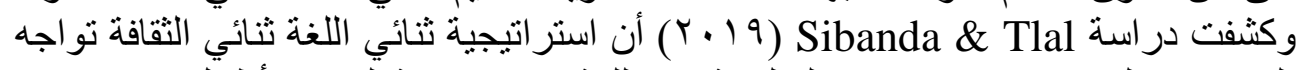

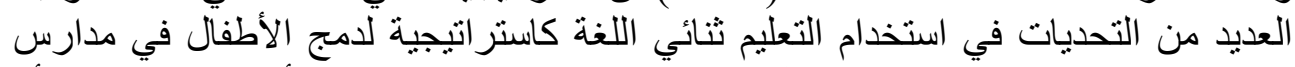

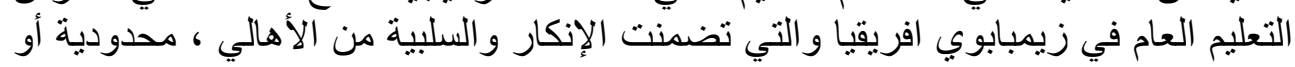

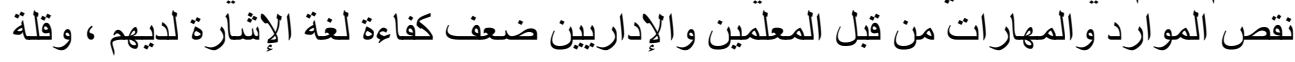

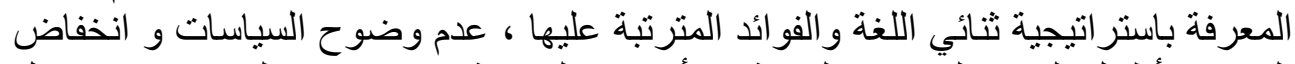

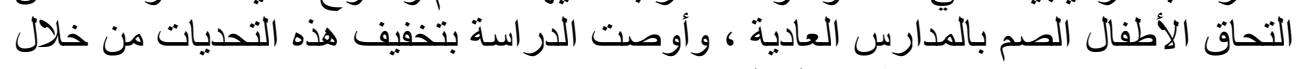

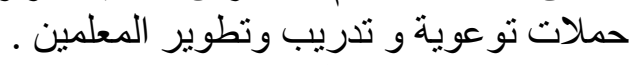

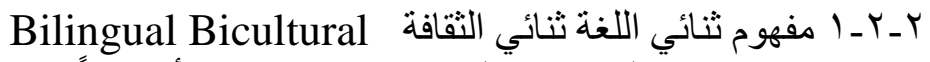

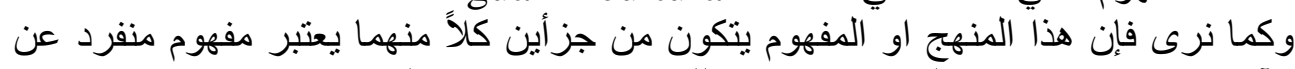

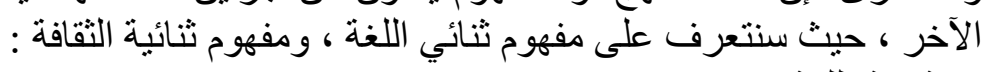

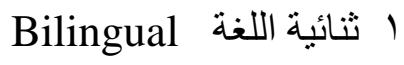




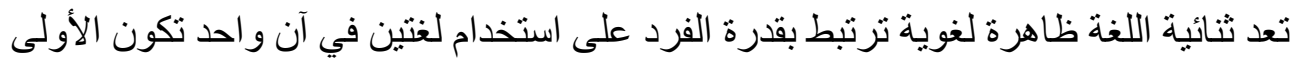

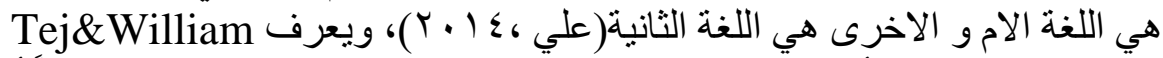

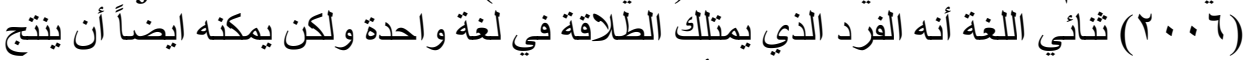

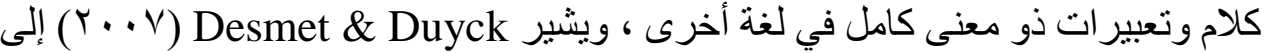

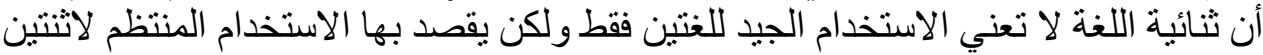

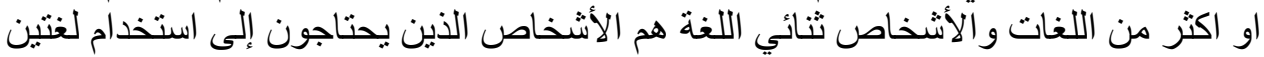

$$
\text { او اكثر في حياتهم اليومية. }
$$

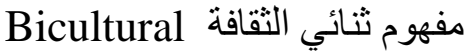

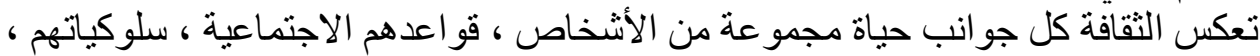

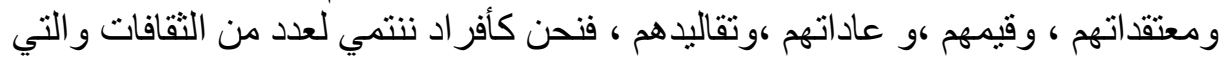

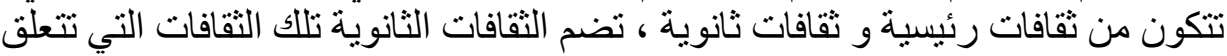

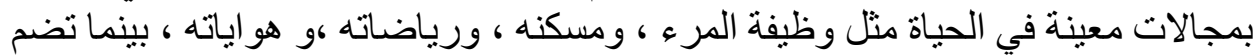

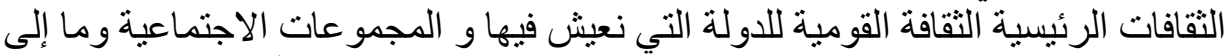

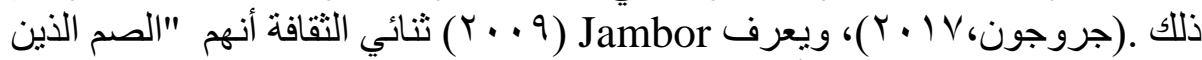

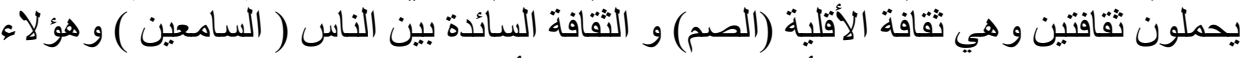

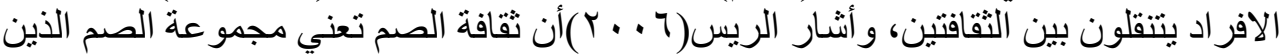

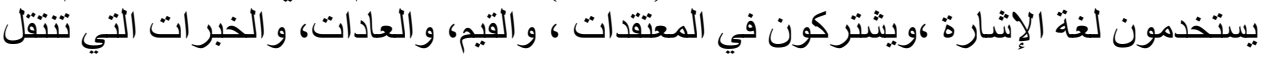

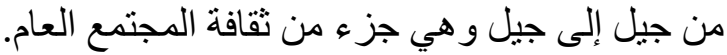

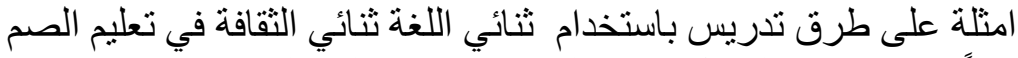

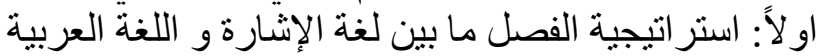

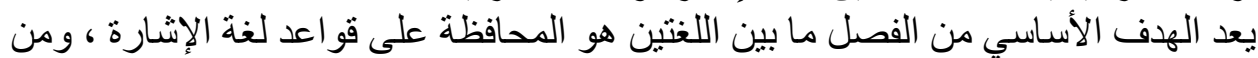

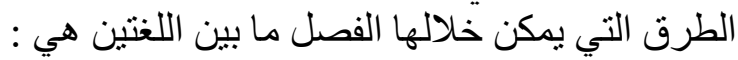

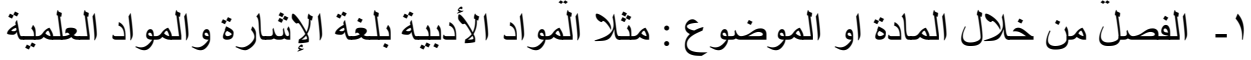
باللغة العربية . r- الفصل عن طريق الأشخاص : مثنلا مدرس يستخدم لغة الإشارة و مدرس آخر يستخدم

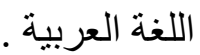

r- الفصل من خلال الزمن : مثثلا اول حصة در اسية بلغة الإشارة و الثانية باللغة العربية و هكذا. عـ الفصل من خلال المكان : مثنلا في مكتبة المدرسة يتم استخدام اللغة العربية وفي معمل العلوم تستخدم لغة الإشتارة . 0ـ الفصل من خلال نوع النشاط التعليمي : مثنا المناقثة بلغة الإثارة و التلخيص باللغة العربية . 


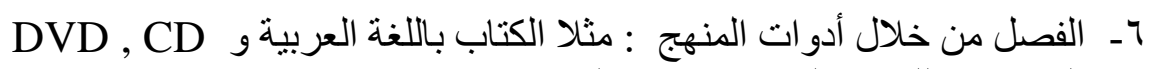

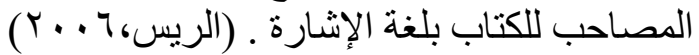

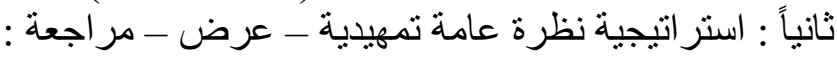
يتم تطبيق استر اتيجية (PVR) في تدريس اللغة الثانية للطلاب الصم وفية وفقاً لخطو ات ومر احلة

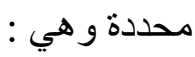

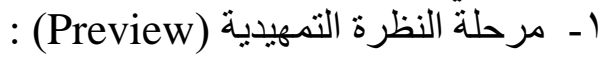

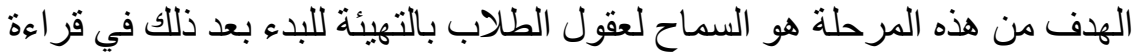

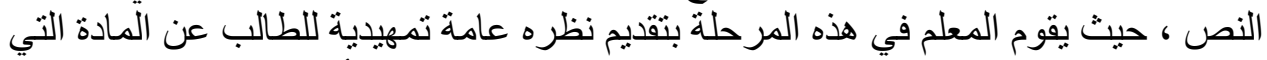

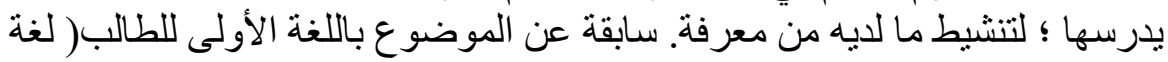

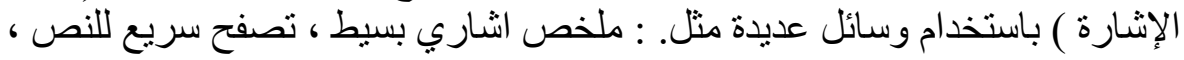

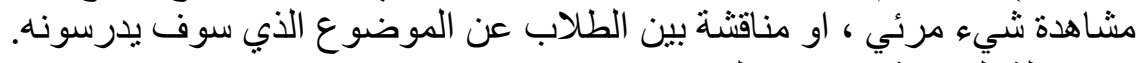

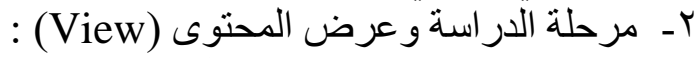

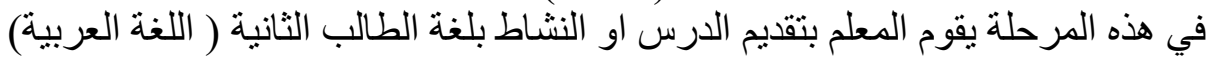

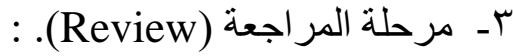

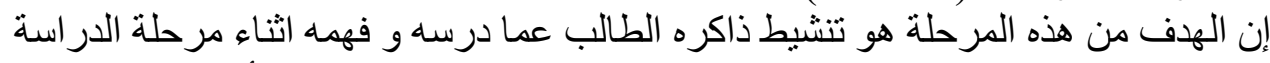

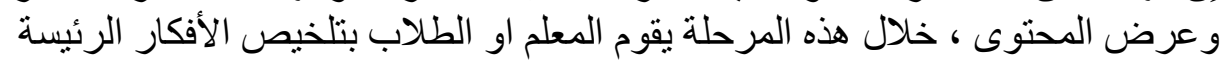

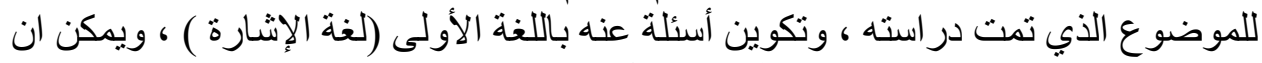

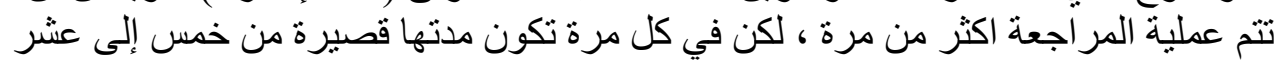

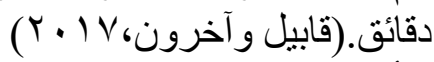

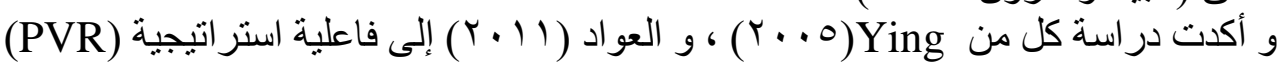

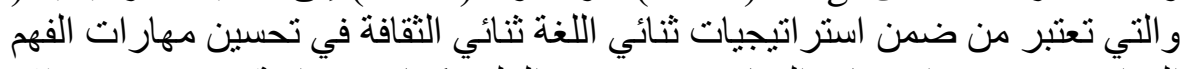

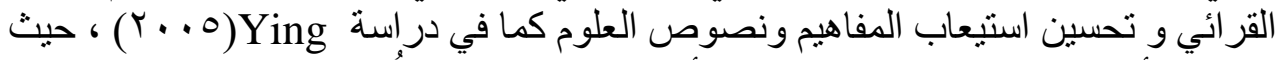

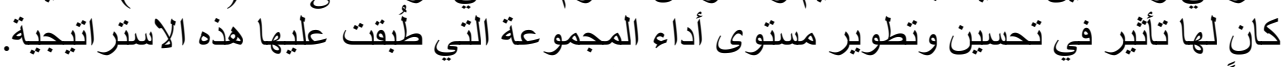

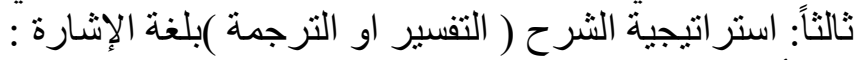

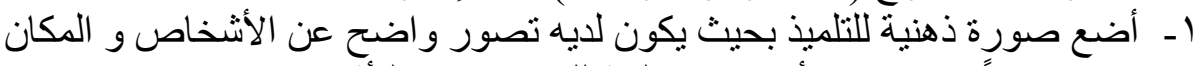

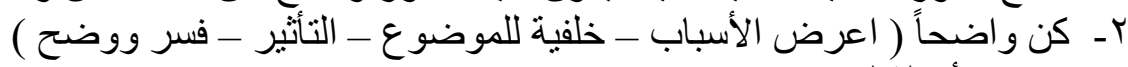

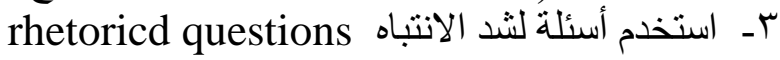

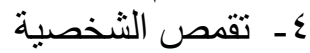

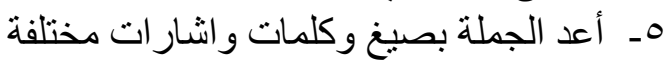

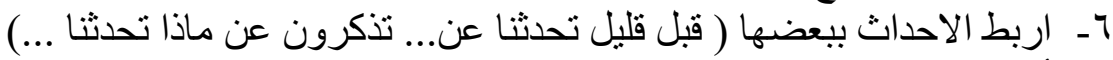

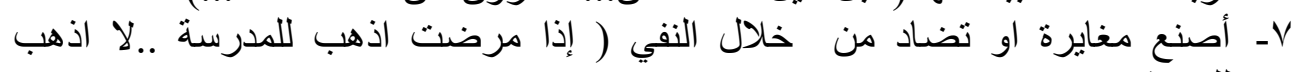
اللمستشفى ( 
1ـ - لخص الأفكار المطروحة

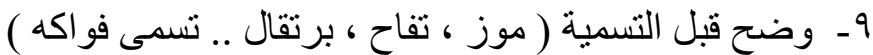

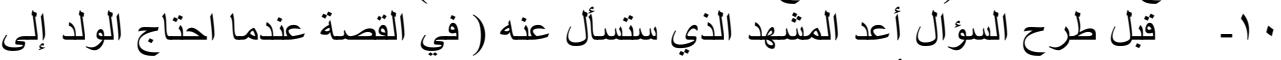

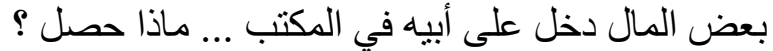

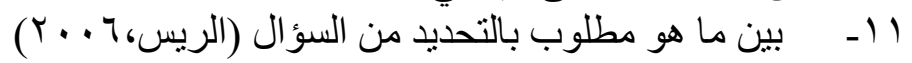

الدر اسات السابقة

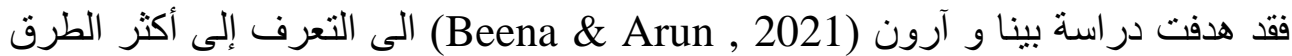

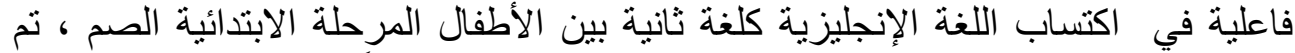

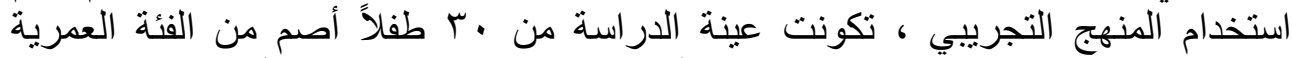

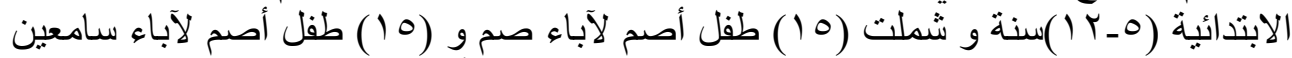

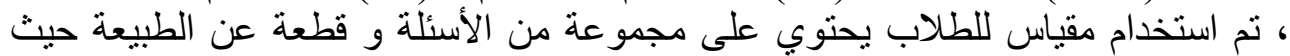

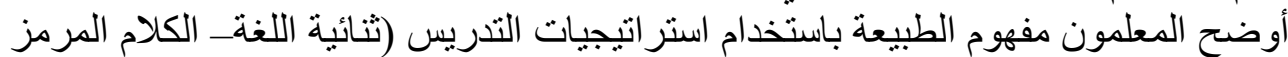

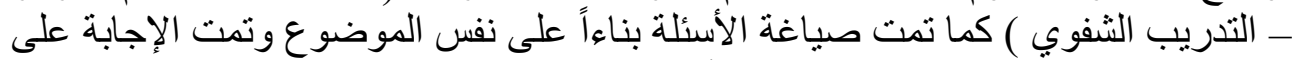

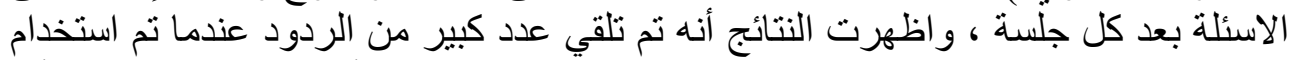

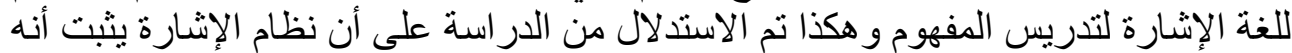

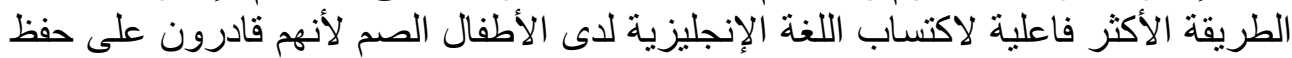
المفهوم بوضوح وفئر فاعه الأفكار و إعادة إنتاجها.

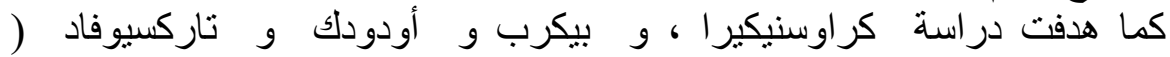
إلى 2020 ، Krausnekera \& Beckerb \& Audeoudc \& Tarcsiovád

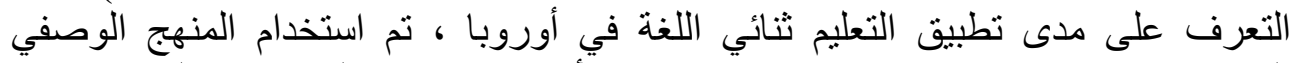

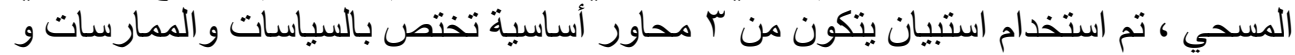

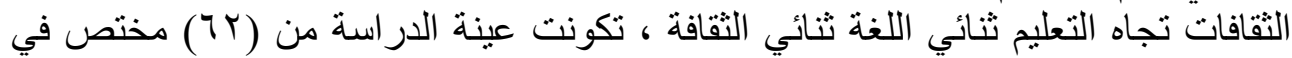

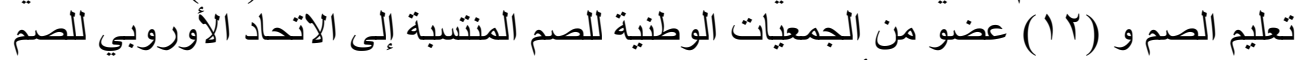

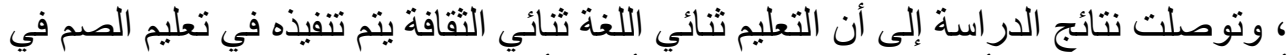

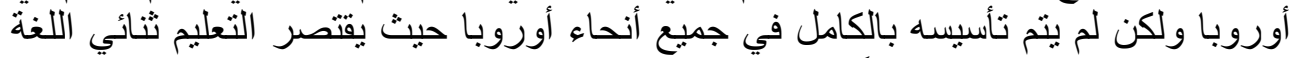

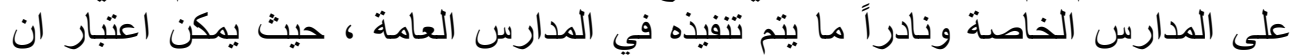

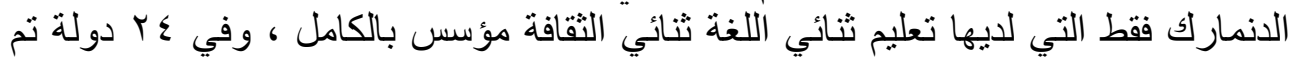

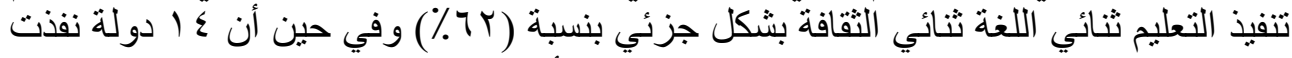

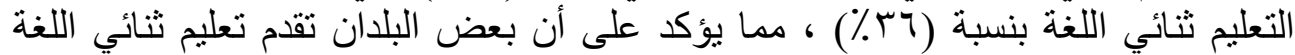
للطلاب الصم بلغة الإشارة الوطنية الخاصة بها ولكنها تفتقر إلى الأسس القانونية والفية والمنهجية 


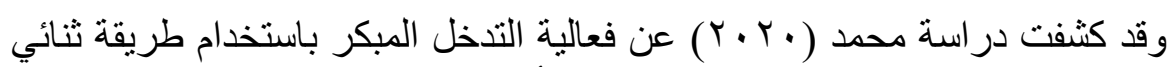

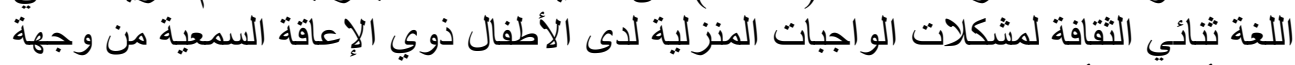

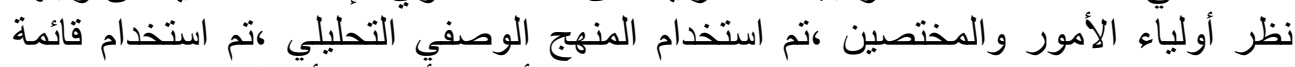

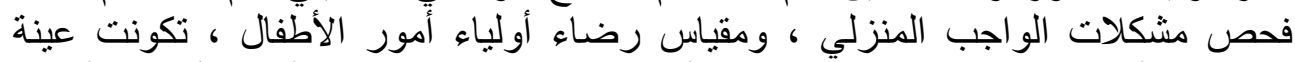

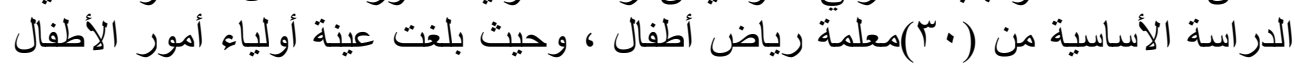

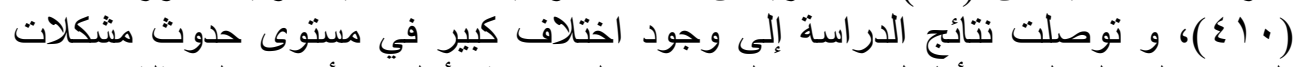

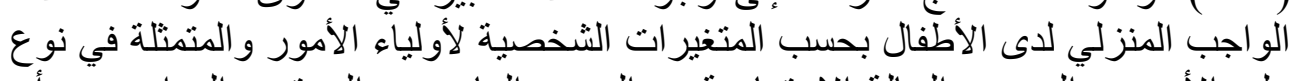

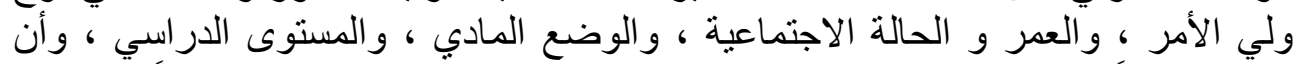

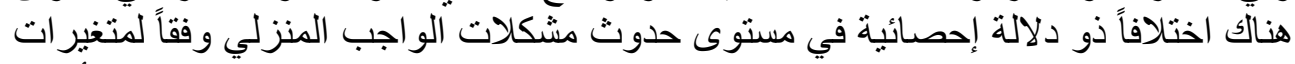

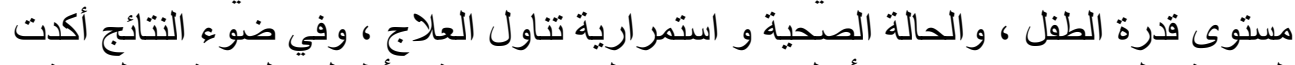

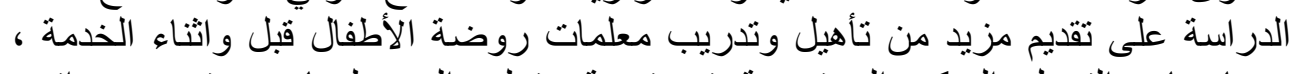

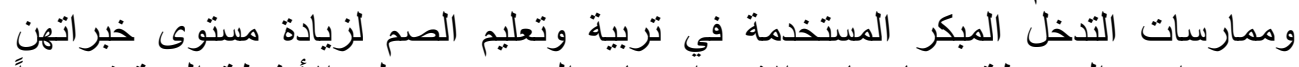

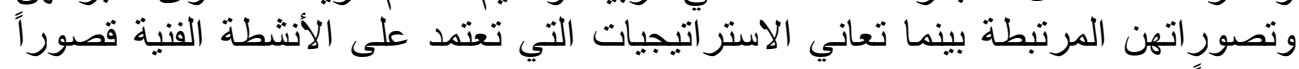

كما كثفت دراسة سيباندا و تلال ( Sibanda \& Tlale 2019 ) عن التحديات و واضحاً.

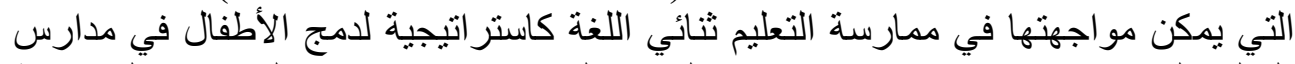

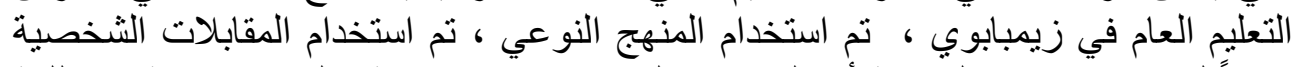

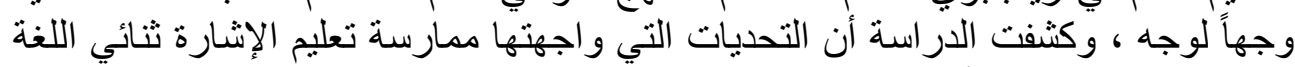

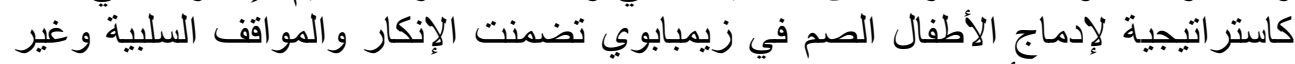

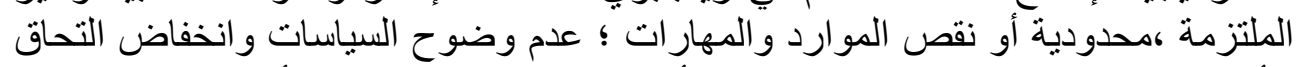

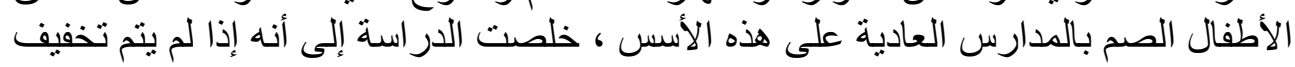

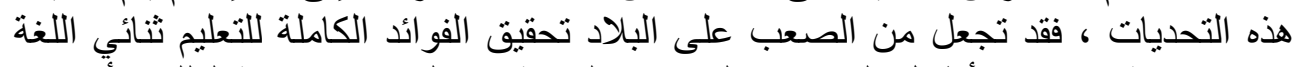

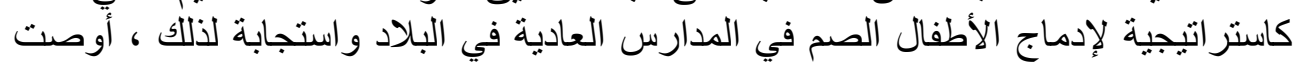

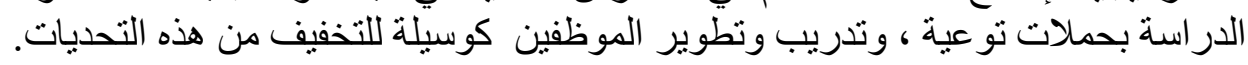

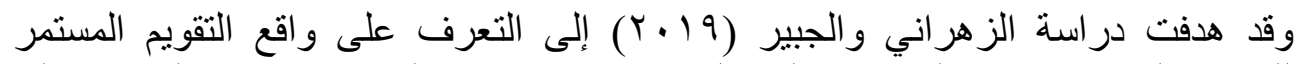

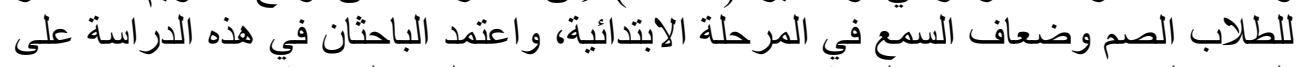

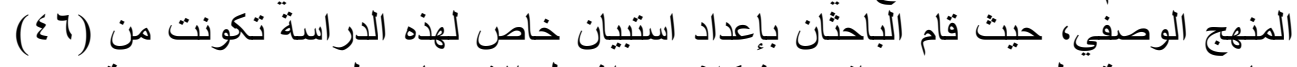

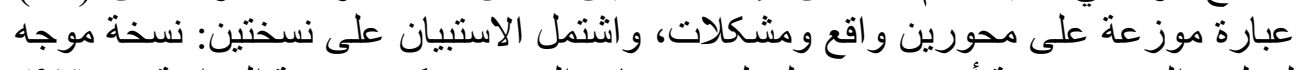

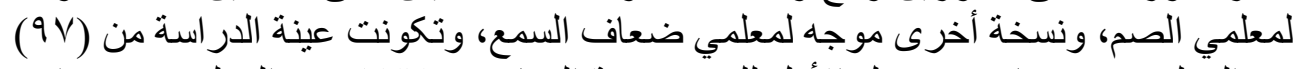

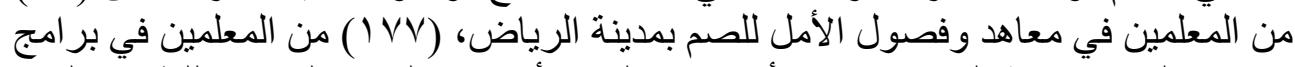

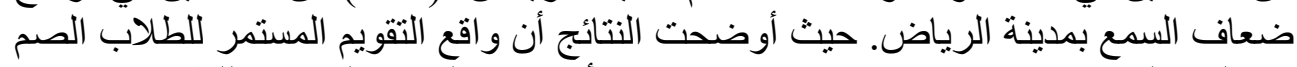

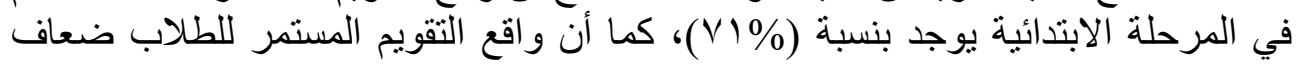




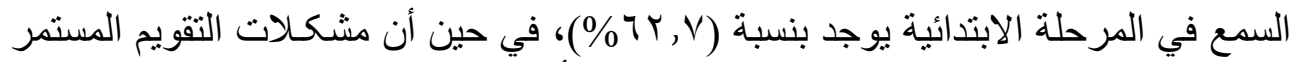

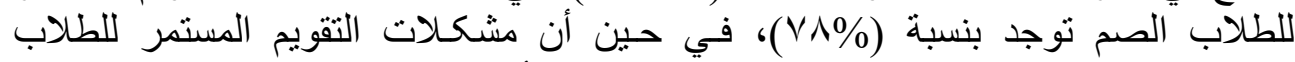

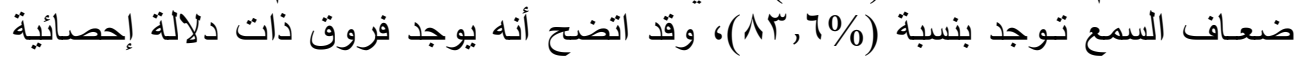

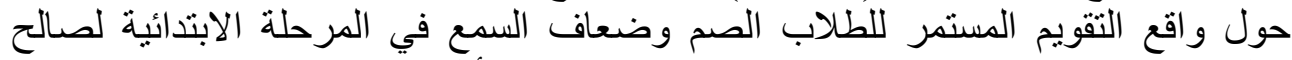

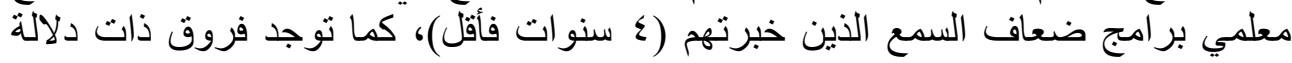
إحصائية حول مشكلات التقويم المستمر للطلاب الصم وضعاف الهين السمع في المرحلة الابتدائية باختلاف متغير المؤهل التعليمي لصالح

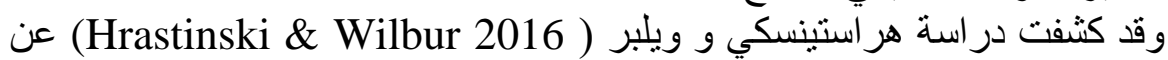

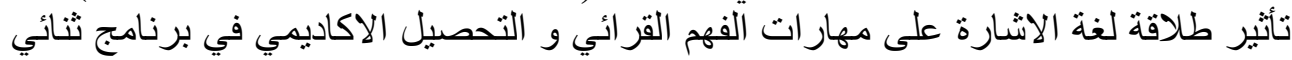

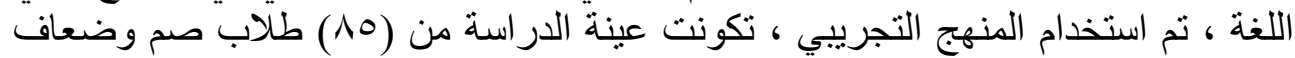

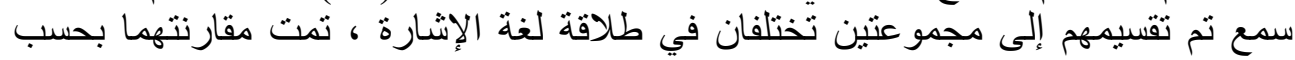

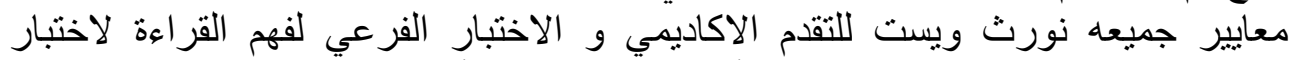

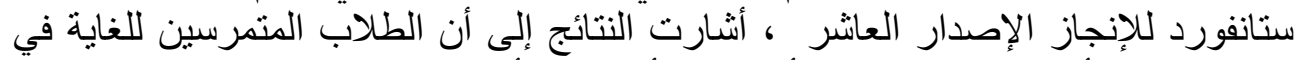

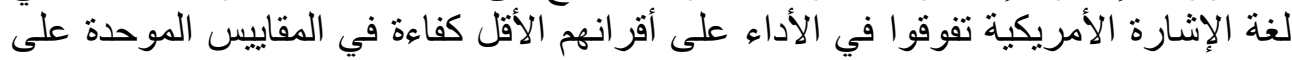

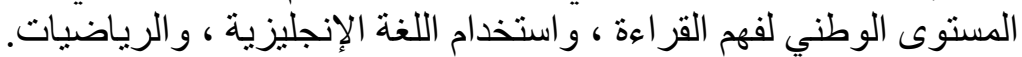

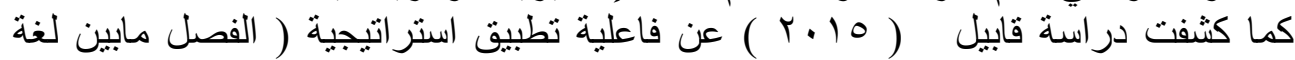

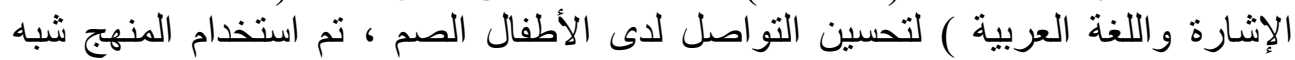

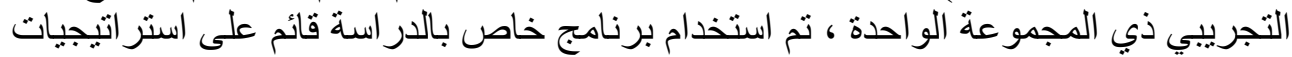

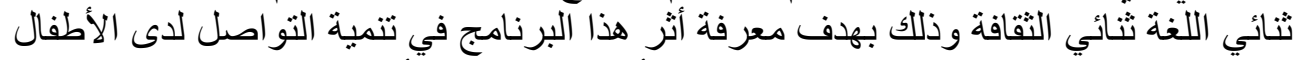

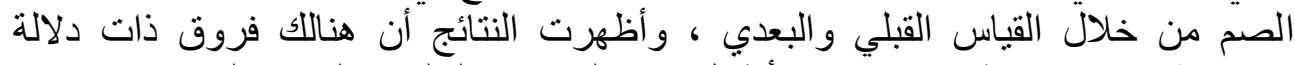

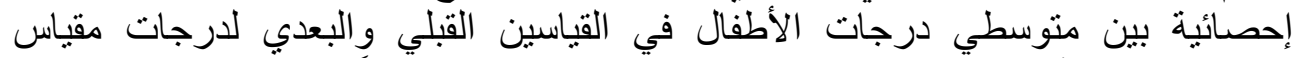

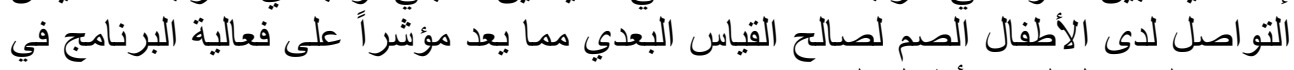

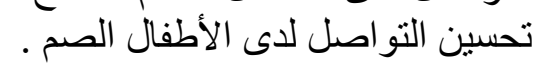

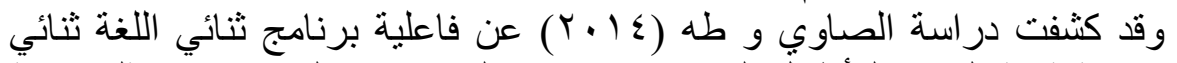

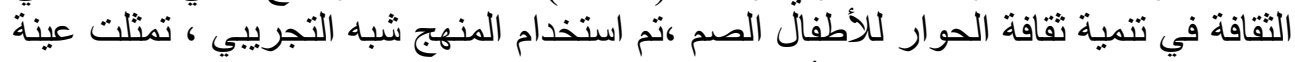

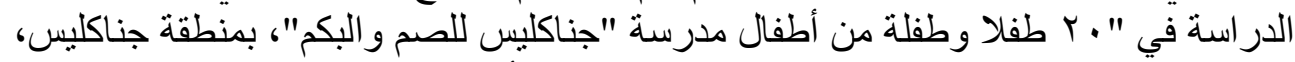

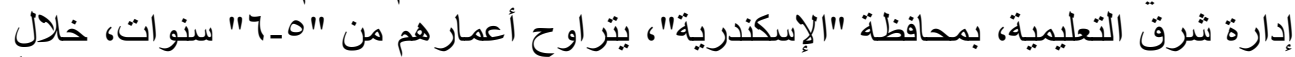

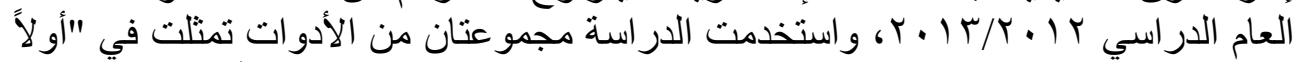

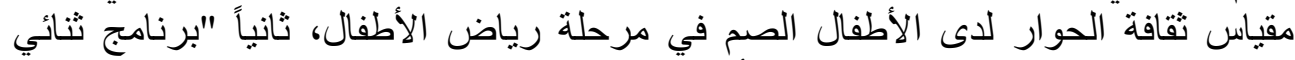

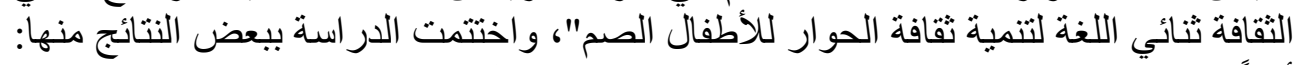

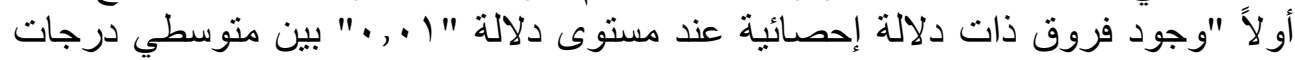

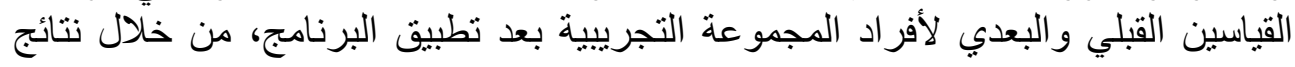




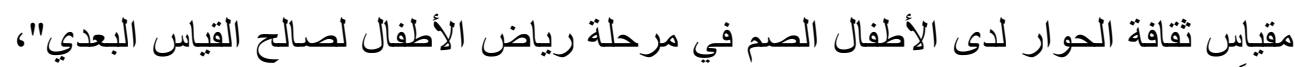

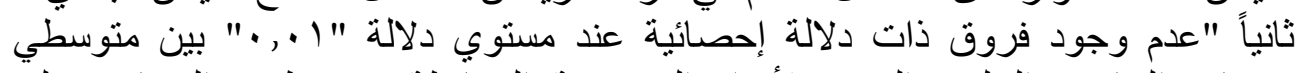

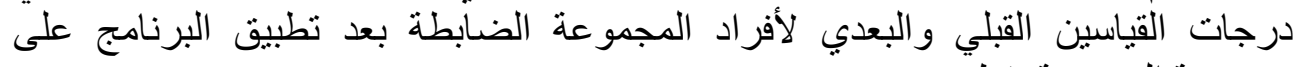
مجمو عة التجريبية فقط.

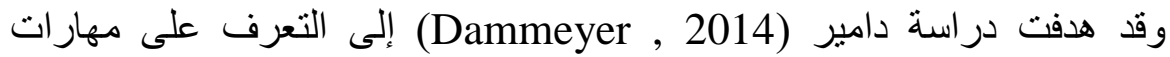

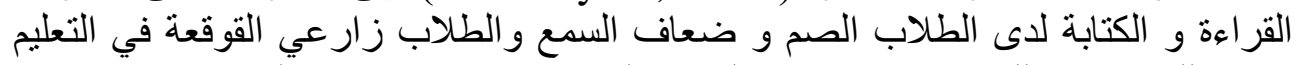

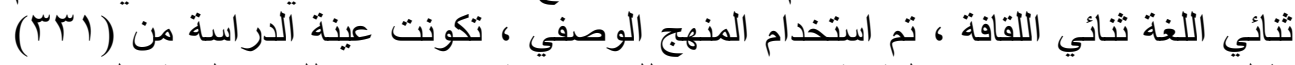

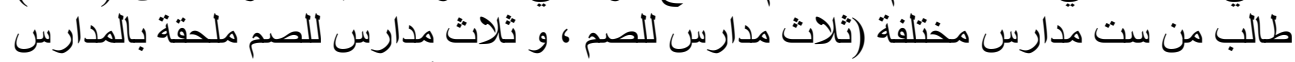

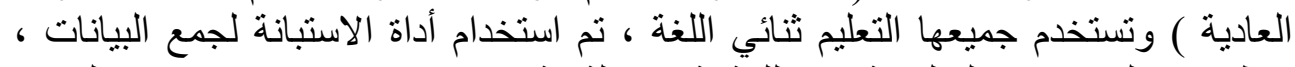

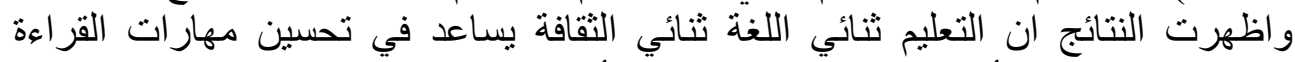

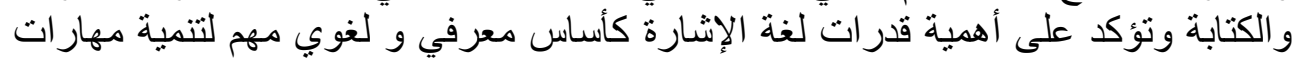

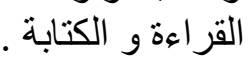

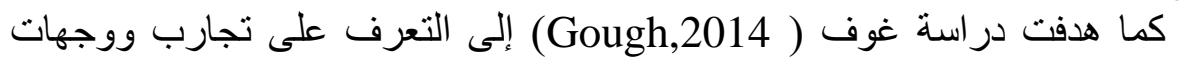

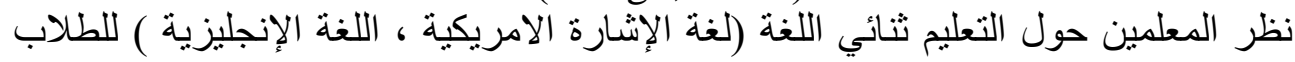

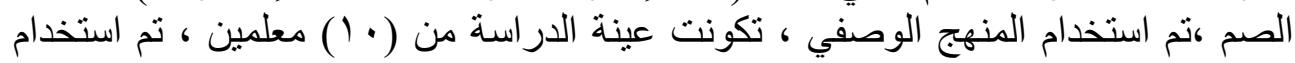

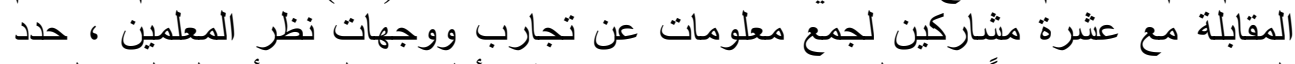

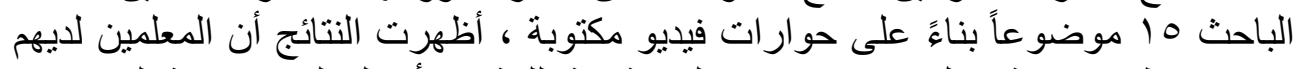

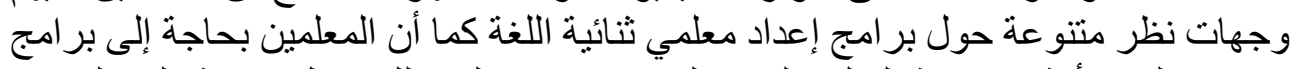

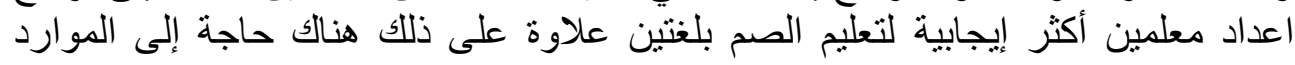

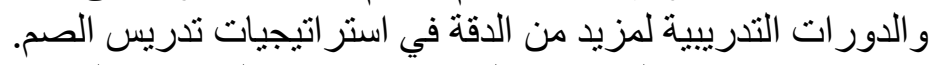

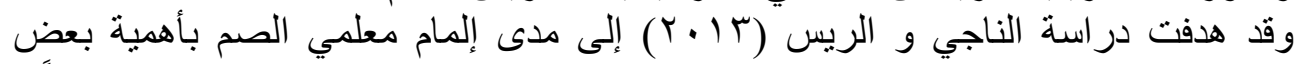

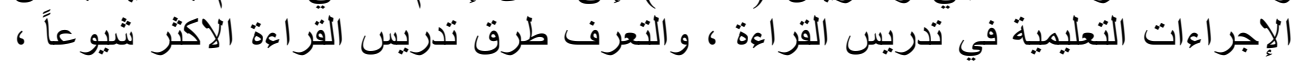

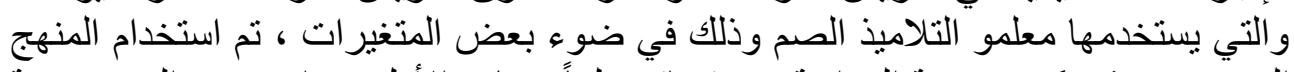

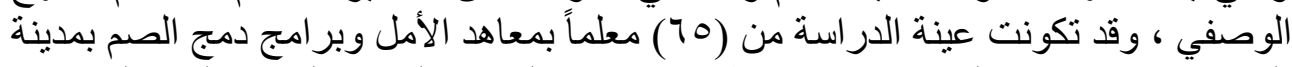

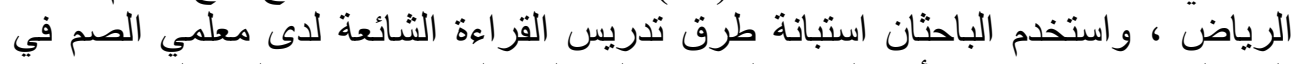

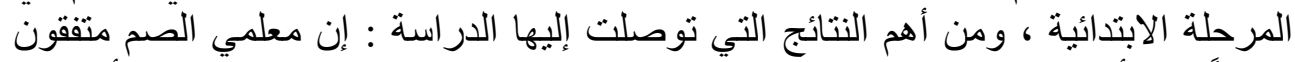

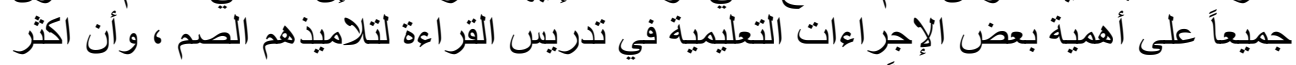

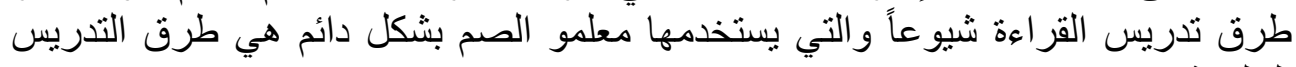
التقليدية.

التعقيب على الار اسات السابقة 
لقد بحثت الدر اسات العربية و الأجنبية في موضوع استر اتيجية ثنائي اللغة ثنائي

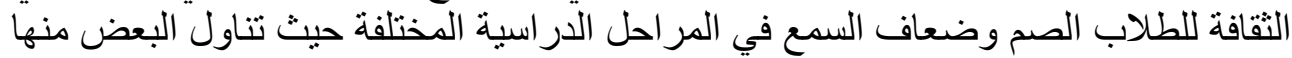

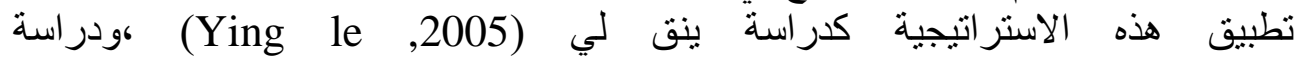

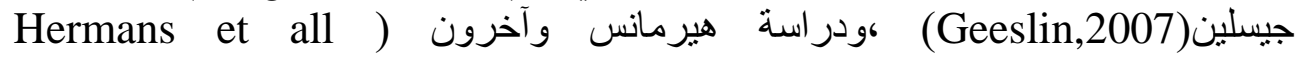

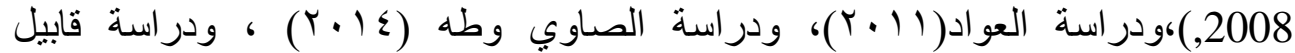

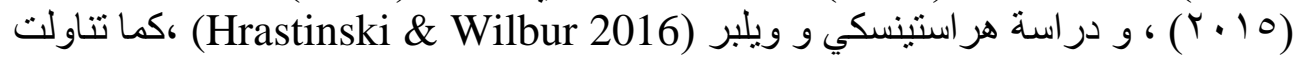

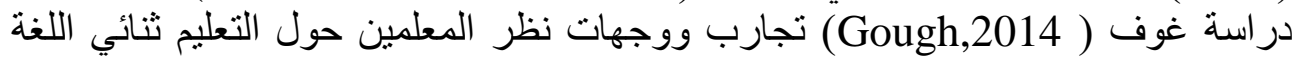

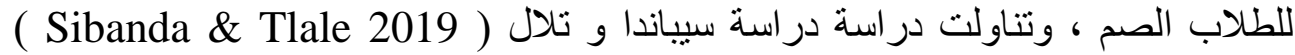

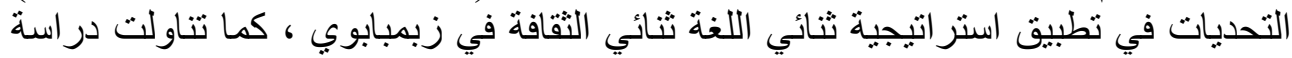

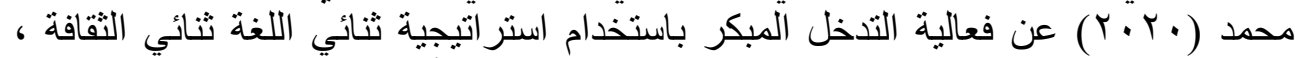

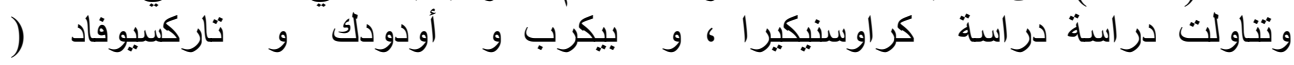
، Krausnekera \& Beckerb \& Audeoudc \& Tarcsiovád

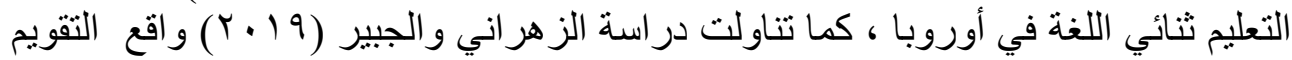

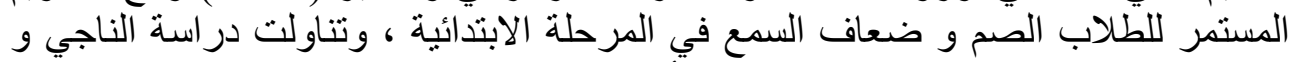

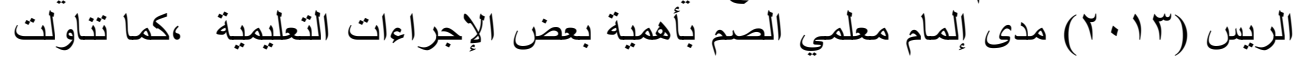

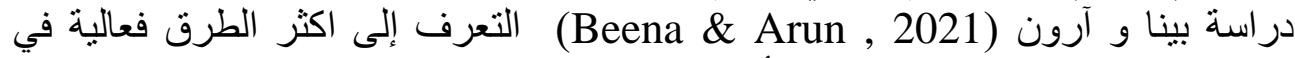

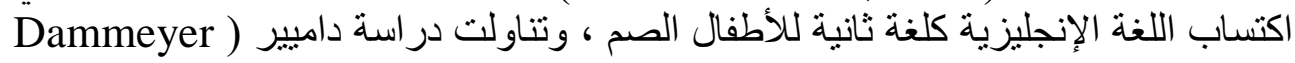

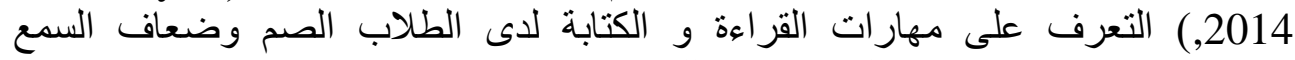

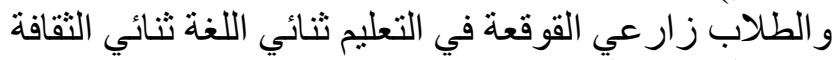

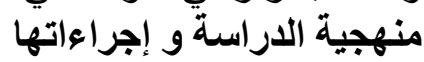
منهج الاراسة منهة الارلة

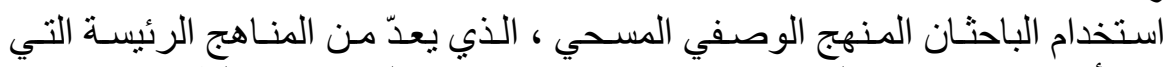

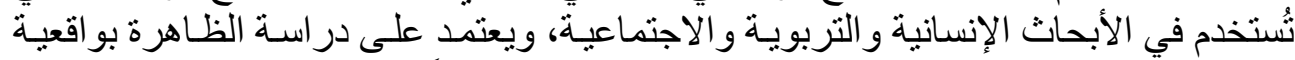

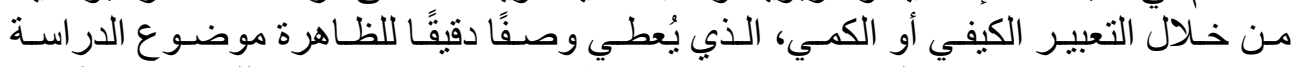

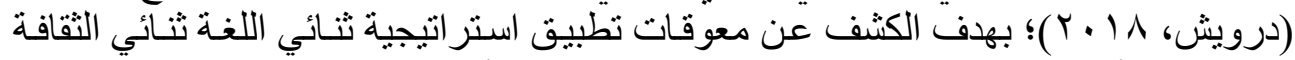

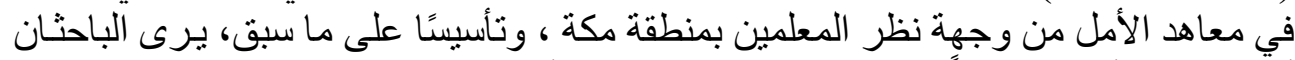

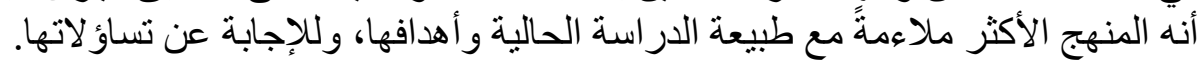

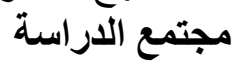

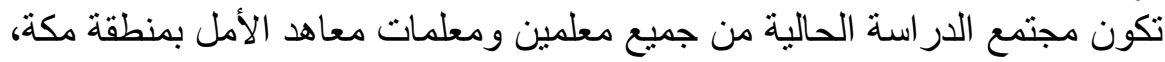

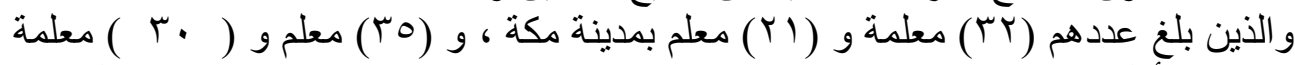

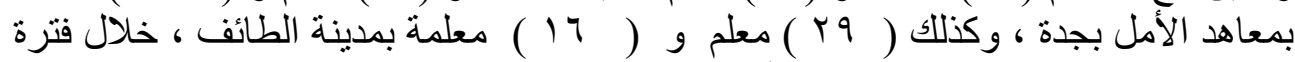

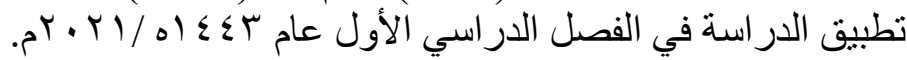




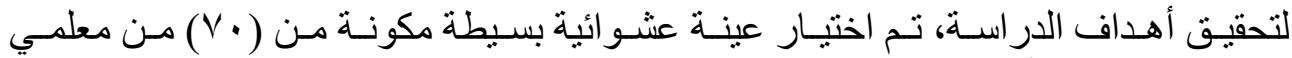
ومعلمات معاهد الأمل بمنطقة مكة.

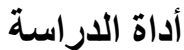

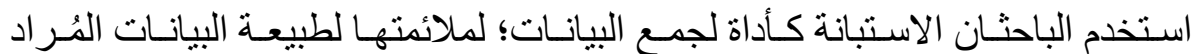

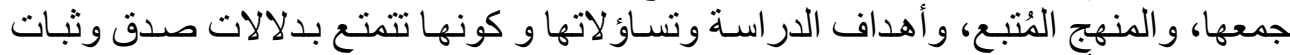

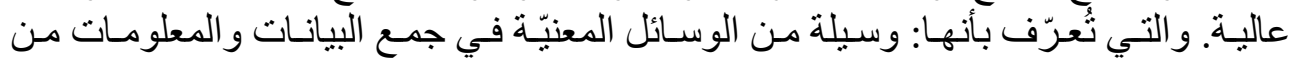

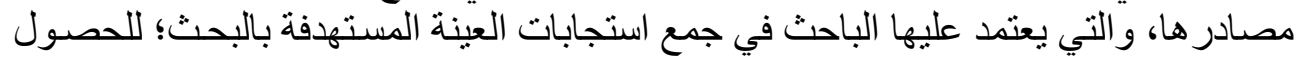
على آر ائهم وتطلّعاتهم. وصف الأداة

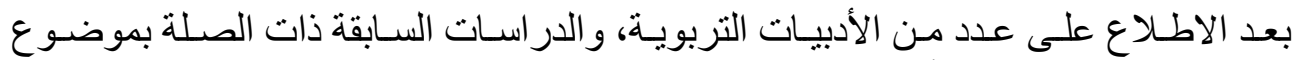

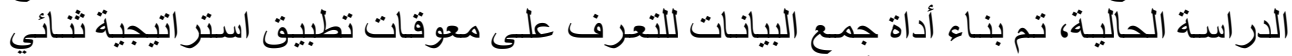

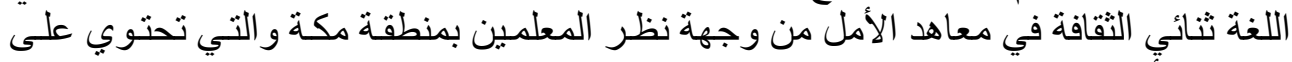
محورين أساسبين، وهما:

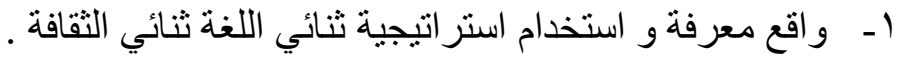

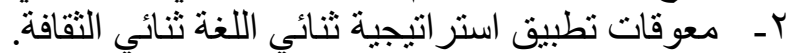
وفيما يلي تفصيل لأداة الدر استة:

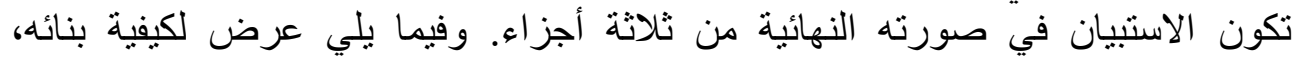

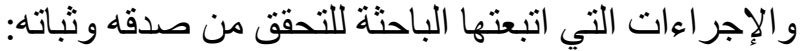

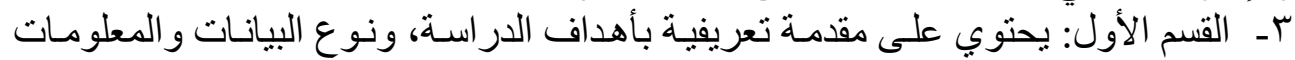

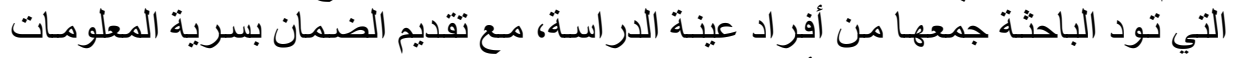

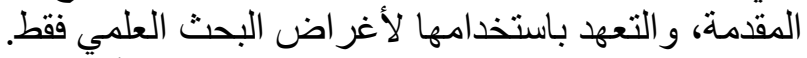

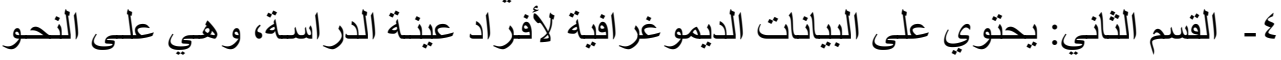

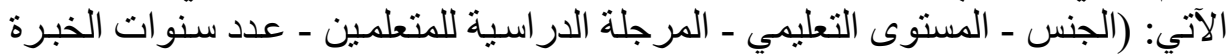

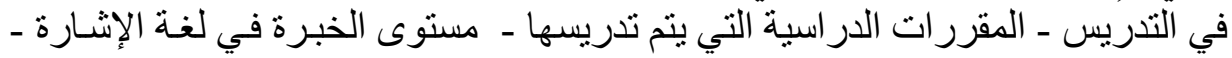

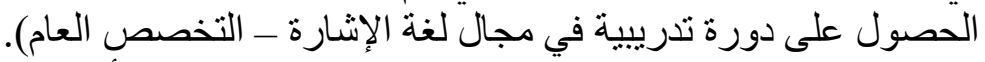

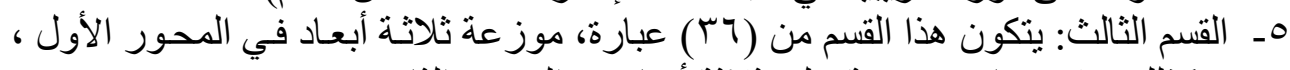

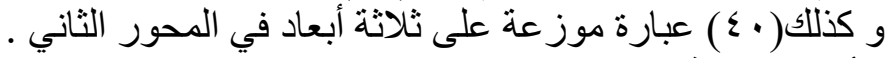
صدق أداة الدراسنة

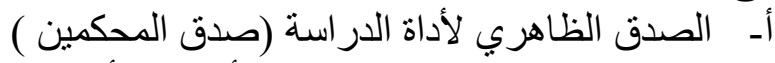

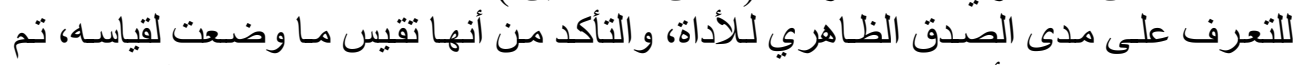

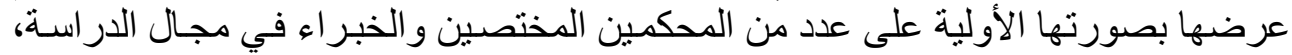




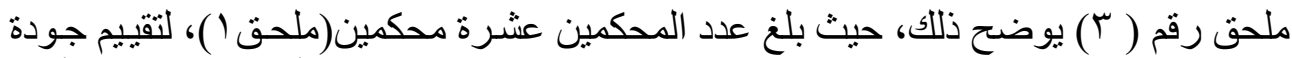

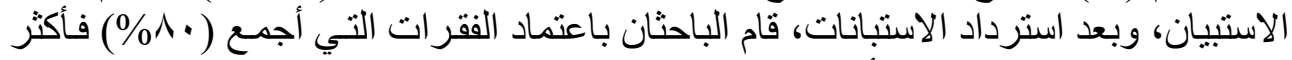

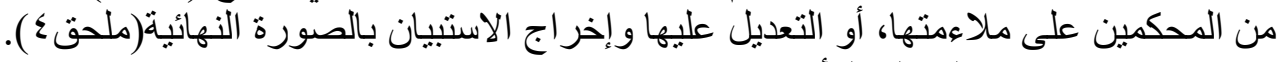

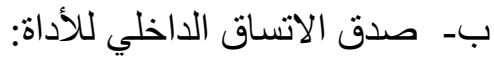

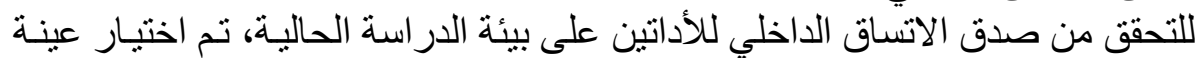

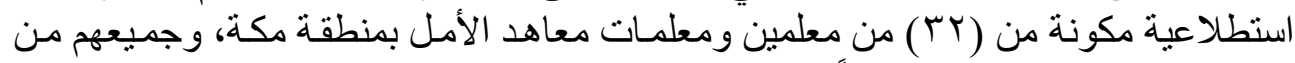

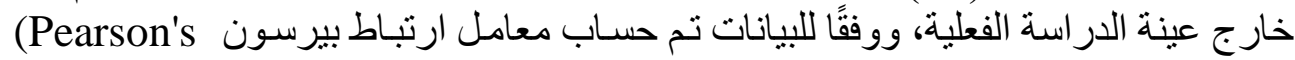
Correlation Coefficient) عبار ات كل استيان بالدرجة الكلية للاستبيان الذي تنتمي إليه العبارة.

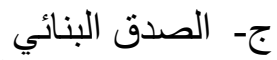

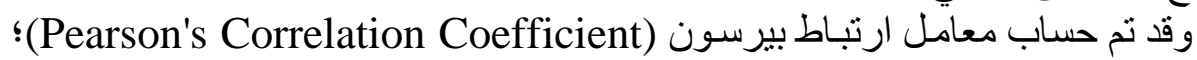
وذلك بهدف التعرف على درجة ارتباط كل بعد من أبعاد كل استبيان بالدرجة الكلية للاستبان

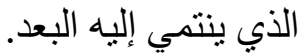

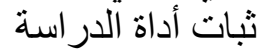
تم التأكد من ثبات أداتي الدراسة من خلال استخدام معامل الثبات ألفا كرونباخ (معادلة ألفا

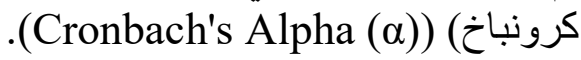
نتائج الدار اسة ومناقتشنها

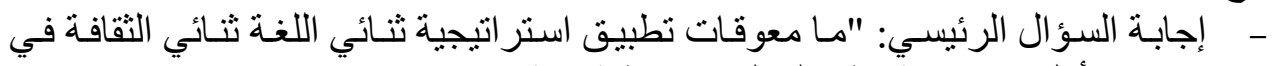

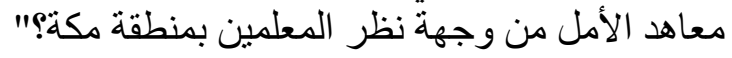

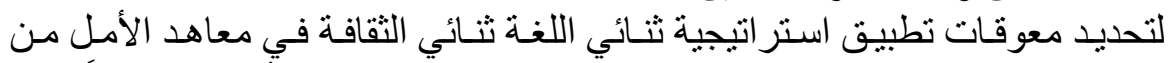

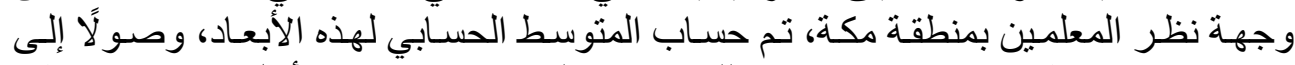

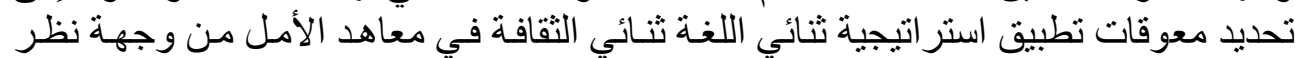

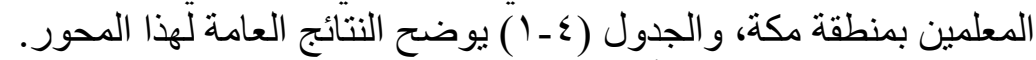

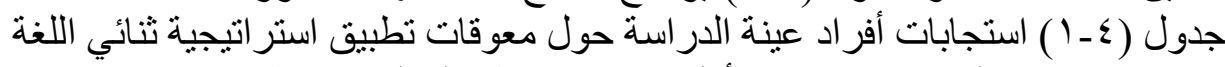

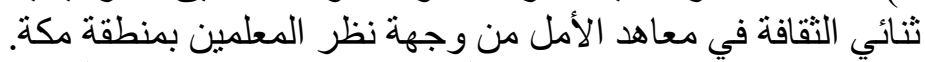

\begin{tabular}{|c|c|c|c|c|c|}
\hline \multirow[b]{2}{*}{ الترتيب } & \multirow[b]{2}{*}{ الالانحراف } & \multicolumn{2}{|c|}{ المتوسط الحسابي } & \multirow[b]{2}{*}{ الأبعاد } & \\
\hline & & درجة المو افقة & المتوسة & & \\
\hline$r$ & .65311 & بدرجة متوسطة & 4.0202 & & \\
\hline & .537 & بدرجة عالية & 4.5824 & معوقات تتعلق بالمناهج الدراسية & \\
\hline & .70367 & 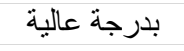 & 4.2614 & المعوقات الإدارية & \\
\hline & .56433 & بدرجة عالية & 4.2632 & 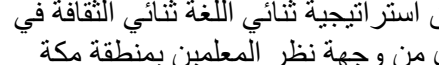 & \\
\hline
\end{tabular}


يتضح من خـلال النتائج أن معوقات تطبيق استر اتيجية ثنائي اللغـة ثنائي الثقافة في وني

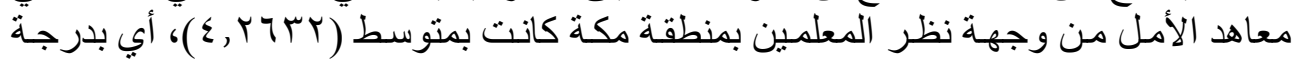

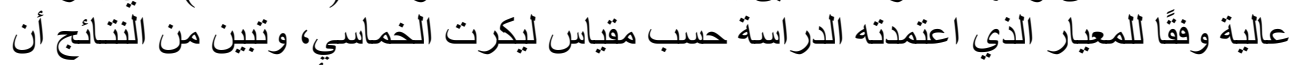

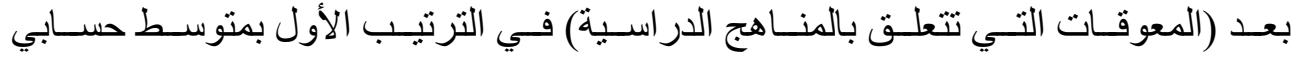

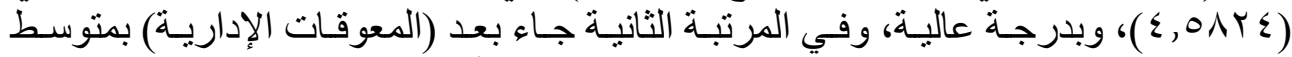

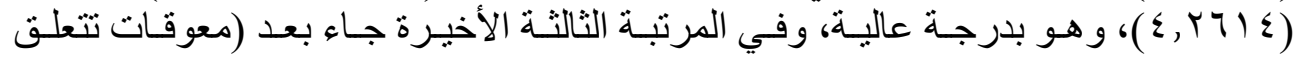

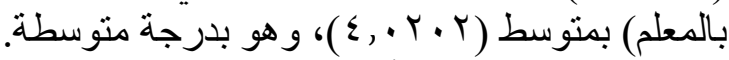

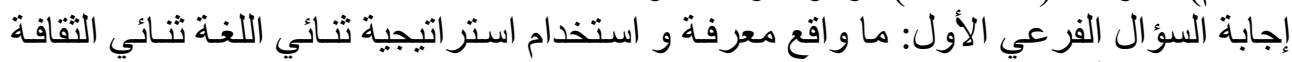

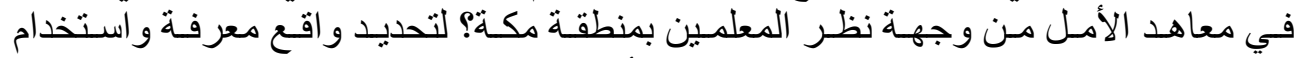

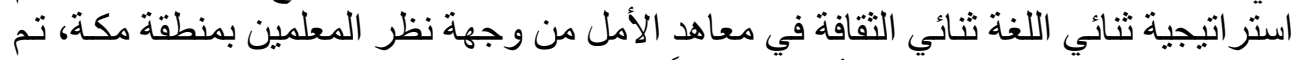

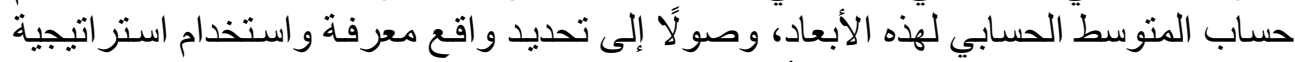

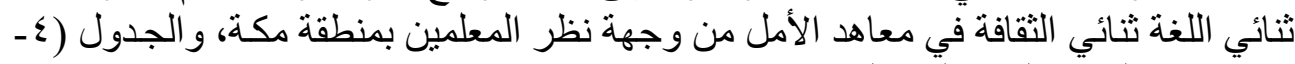

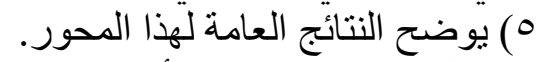

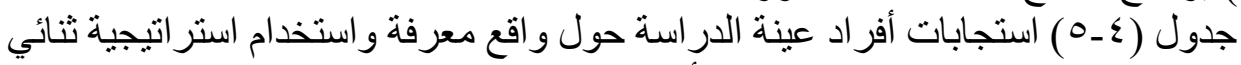
اللغة ثنائي الثقافة في معاهد الأمل من وجهة نظر المع المعلمين بمنطقة مكة.

\begin{tabular}{|c|c|c|c|c|c|c|c|c|c|}
\hline \multicolumn{4}{|c|}{ الإستخدام } & \multicolumn{4}{|c|}{ المعرفة } & \multirow{3}{*}{ الأبعاد } & \multirow{3}{*}{ ك. } \\
\hline \multirow[b]{2}{*}{ الترتيب } & \multirow{2}{*}{ المعياري } & \multicolumn{2}{|c|}{ المتوسط الحسابي } & \multirow[b]{2}{*}{ الترتيب } & \multirow{2}{*}{ الالنحياري } & \multicolumn{2}{|c|}{ المتوسط الحسابي } & & \\
\hline & & دالموجة افقة & قلمتمة & & & المو افقة & المتوسطة & & \\
\hline 1 & .25933 & $\begin{array}{c}\text { أستخدمها } \\
\text { أس }\end{array}$ & 1.9532 & 1 & .41944 & عالية & 4.4506 & التخطيط & 1 \\
\hline r & .34789 & أستخدمها & 1.8156 & r & .51847 & متوسطة & 4.1052 & مرحلة التفيذ & 2 \\
\hline$r$ & .35392 & لا أعرفها & 1.5952 & r & .76652 & متوسطة & 3.5857 & مرحلة & $r$ \\
\hline- & .24894 & أستخدمها & 1.8393 & - & .44562 & متوسطة & 4.1675 & 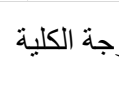 & 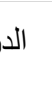 \\
\hline
\end{tabular}

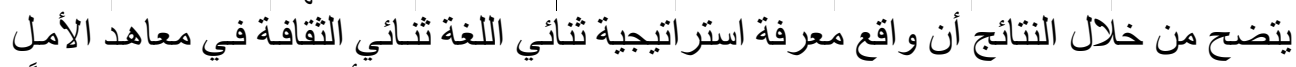

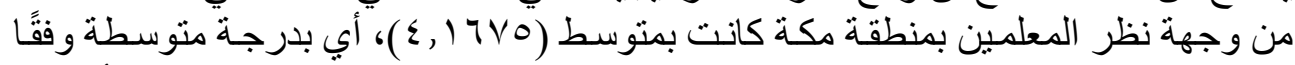

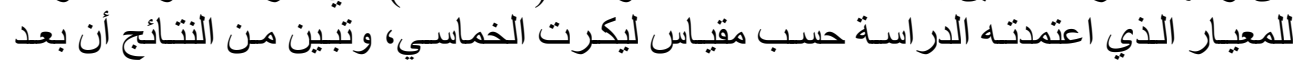

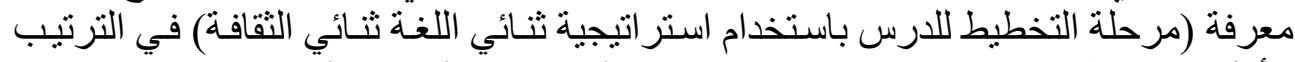

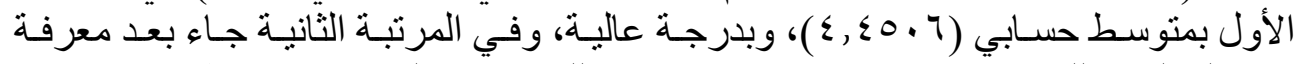

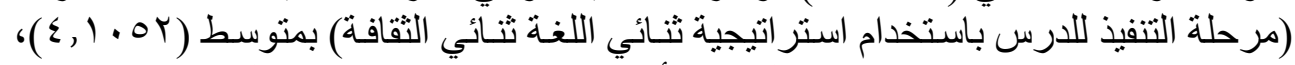

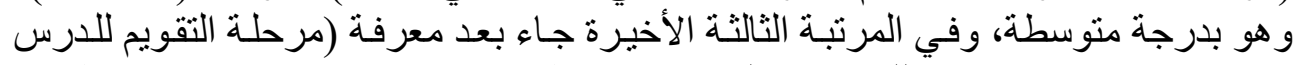

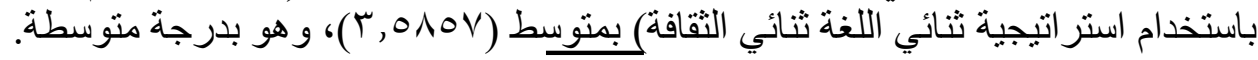




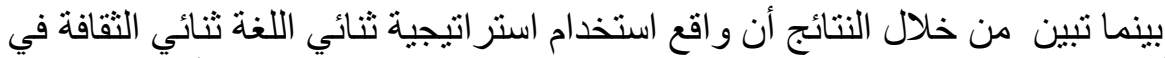

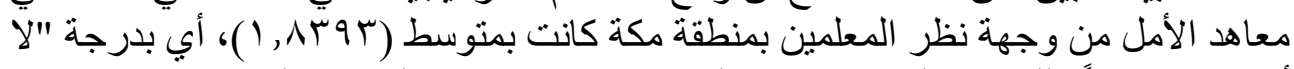

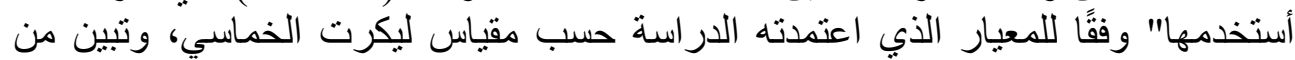

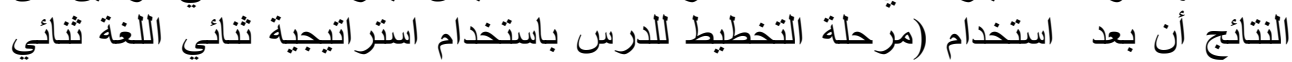

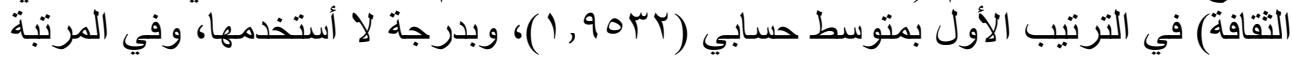

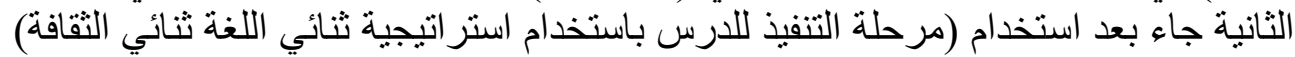

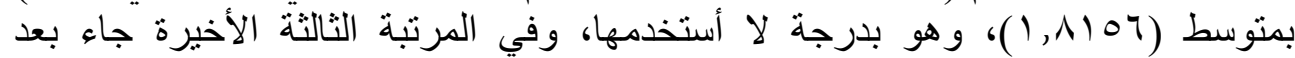

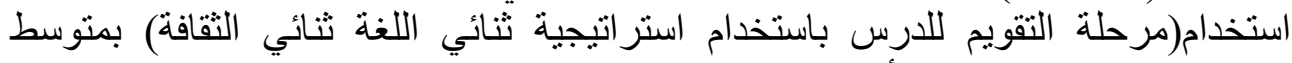

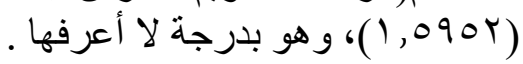

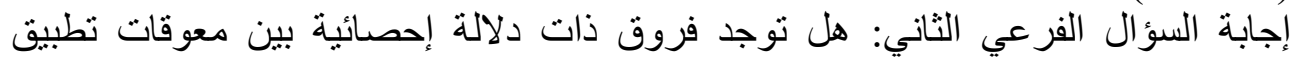

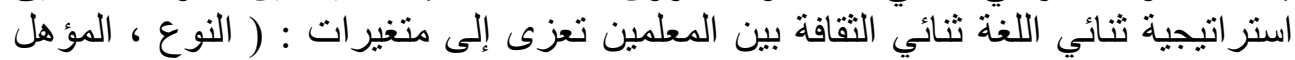

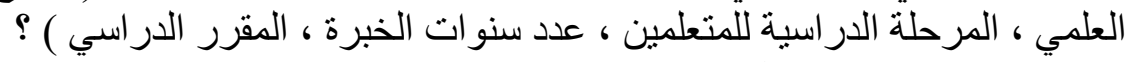

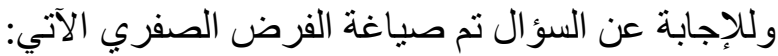

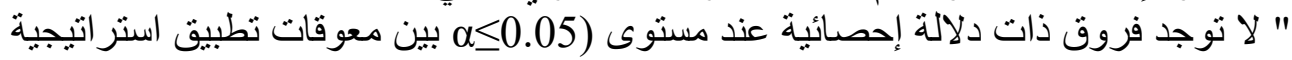

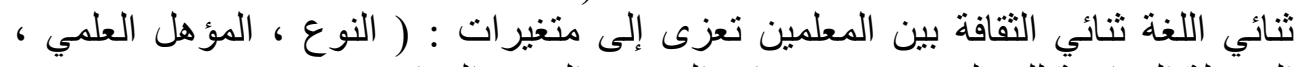

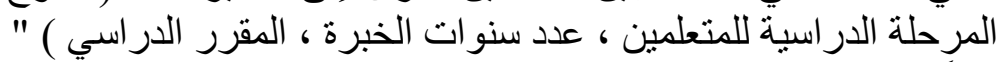
أولاً: متغير النوعة الارنية

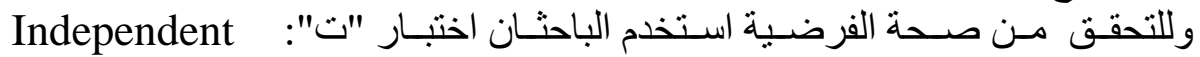

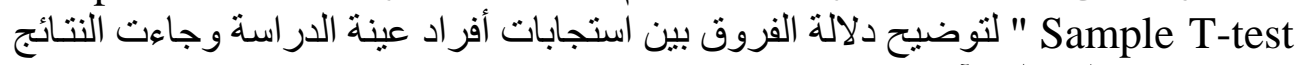

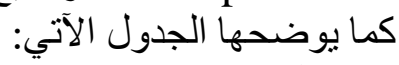

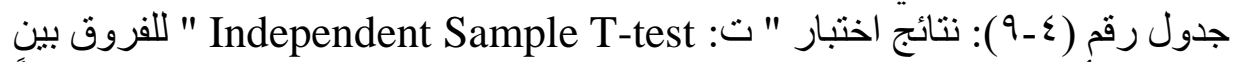

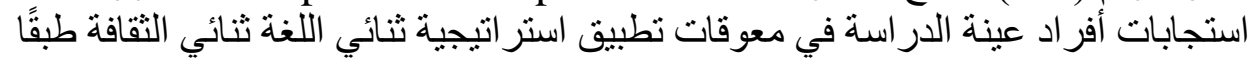
لاختلاف متغير النوع.

\begin{tabular}{|c|c|c|c|c|c|c|c|}
\hline التعليق & الدلالة & قيمة ت & الالانحري اف & المتوسط & العدد & النوع & المحور \\
\hline \multirow[t]{2}{*}{ دالة } & \multirow[t]{2}{*}{$\cdot, \cdot r q$} & \multirow[t]{2}{*}{$r, r \leqslant V$} & .35719 & 4.4125 & 34 & لم كئر & \multirow{2}{*}{ 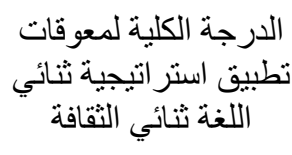 } \\
\hline & & & .68224 & 4.1222 & 36 & أنثى & \\
\hline
\end{tabular}

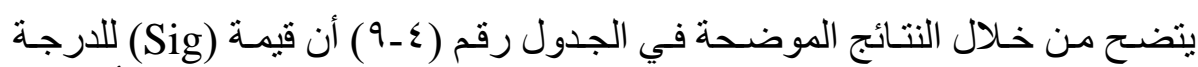

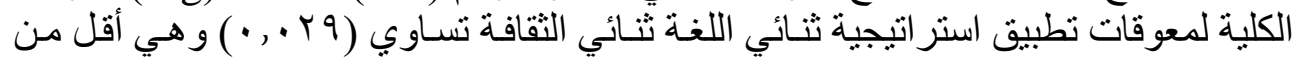

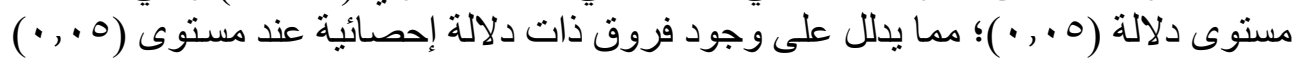




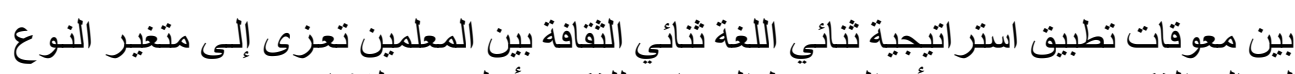

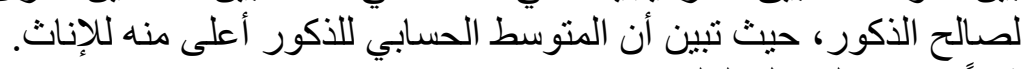

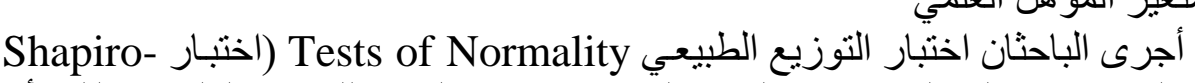

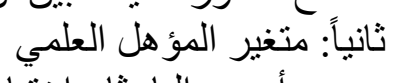

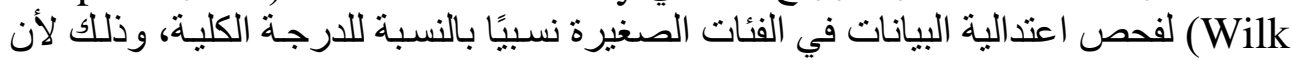

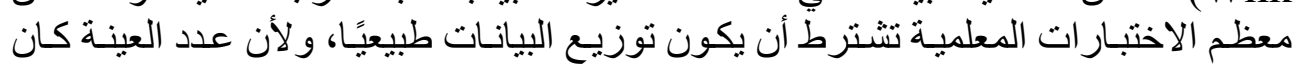

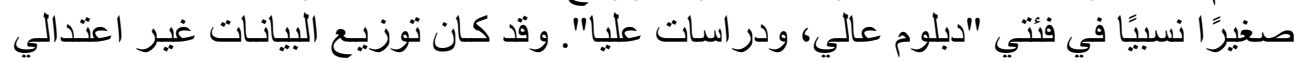

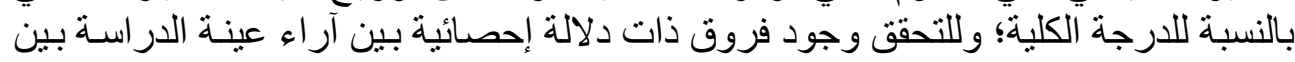

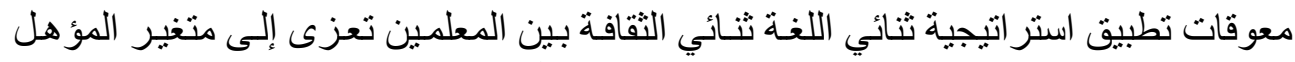

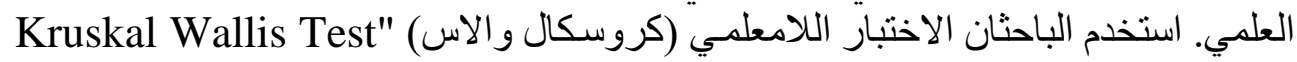

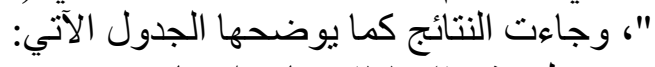

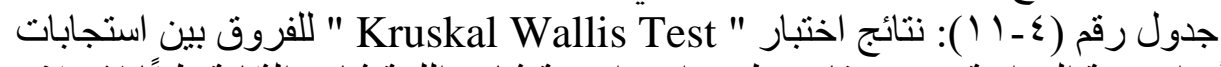

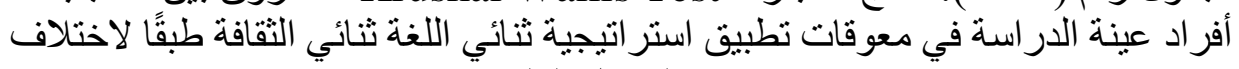

\begin{tabular}{|c|c|c|c|c|c|c|}
\hline التعليق & الدلالة & قيمة مربع & متوسط & العدد & العؤهي & \\
\hline \multirow{3}{*}{ دالة } & \multirow{3}{*}{ • } & \multirow{3}{*}{$r, q 1}$. & 32.67 & 47 & بكالوريوس & \multirow{3}{*}{ تطبيق استرائتيجية لثنائية الثياتي } \\
\hline & & & 39.7 & 12 & & \\
\hline & & & 42.95 & 11 & در اسات علَيا & \\
\hline
\end{tabular}

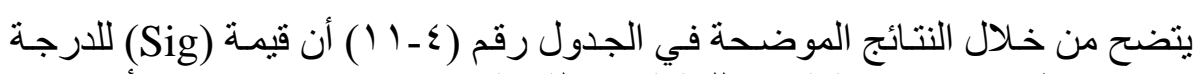

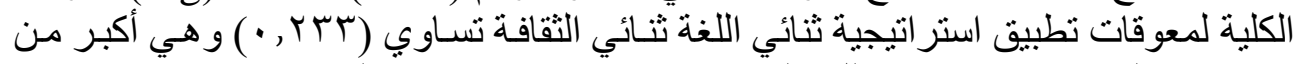

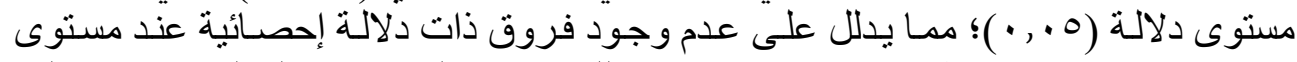

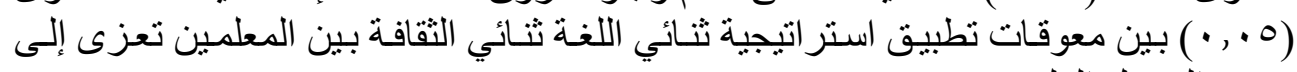

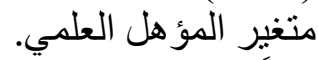

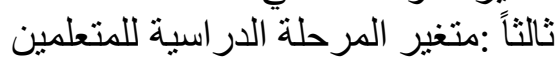

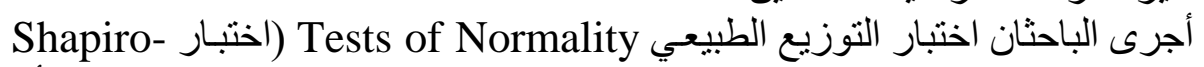
(Wilk

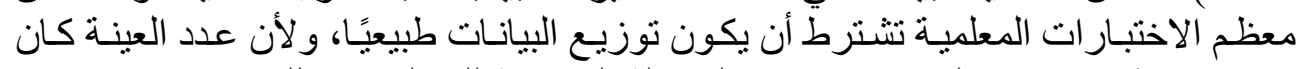

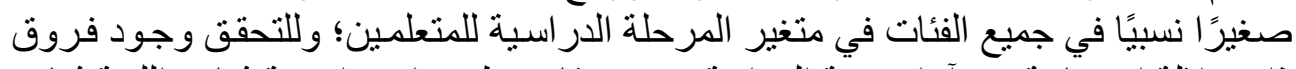

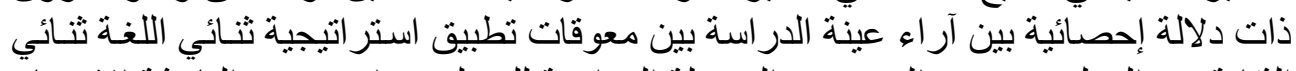

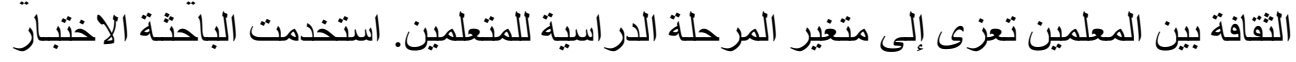


اللامعلمي (كروسكال والاس) "Kruskal Wallis Test "، وجاءت النتائج كما يوضحها

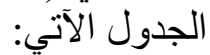

جدول رقم (ع Y Y I ): نتائج اختبار " Kruskal Wallis Test " للفروق بين استجابات

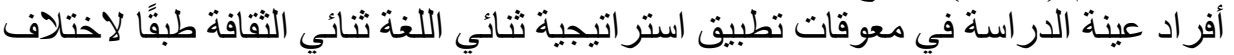
متغير المرحلة الدر اسية للمتعلمين.

\begin{tabular}{|c|c|c|c|c|c|c|}
\hline التعليق & الدلالة & قيمة مربع & متوسط & العدد & اللمتعلمينة الدرحية & \\
\hline \multirow{3}{*}{ غالة } & \multirow{3}{*}{$\cdot, 194$} & \multirow{3}{*}{$r, r q \wedge$} & 29.00 & 22 & ابتدائي & \multirow{3}{*}{ الدبيق استر التية لمبية ثنائي } \\
\hline & & & 38.02 & 23 & متوسط & \\
\hline & & & 38.90 & 25 & ثانوي & \\
\hline
\end{tabular}

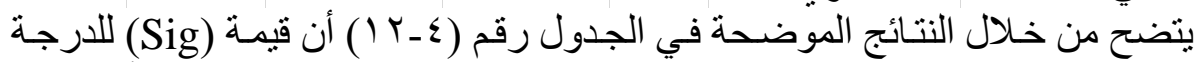

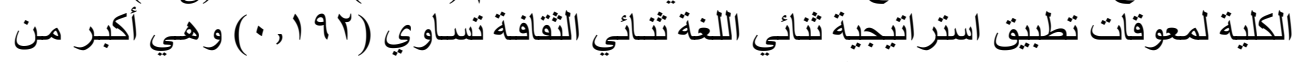

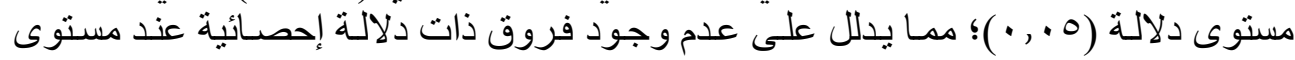

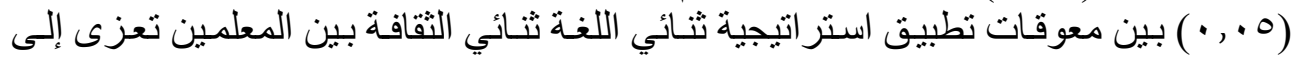
متغير المرحلة الدر اسية للمتعلمين.

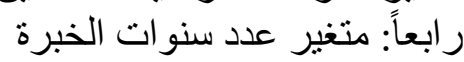

أجرى الباحثان اختبار التوزيع الطبيعي Tests of Normality

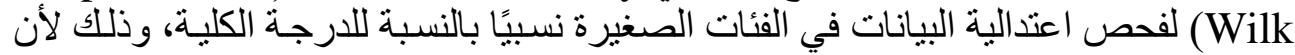

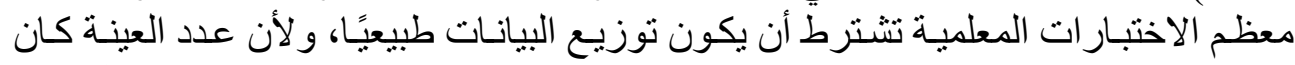

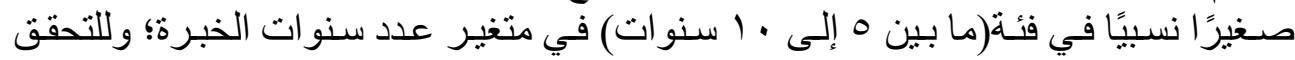

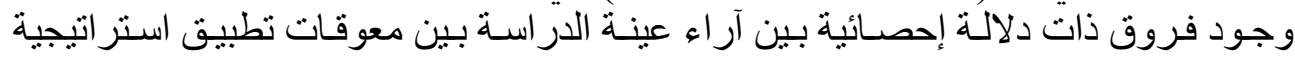

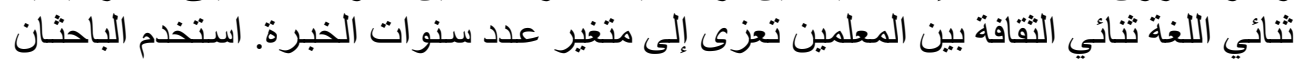

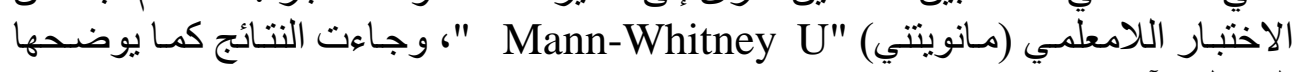

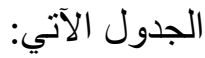




\section{ضي النفيعي -د .احمل عيسى معوقات تطبيق استر اتيجية ثنائي اللغة ثنائي...}

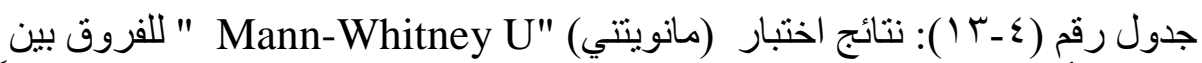

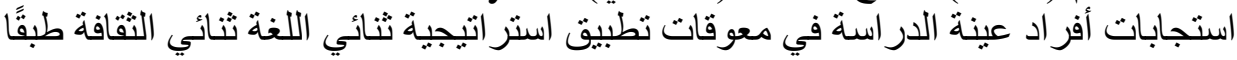
لاختلاف متغير عدد سنوات الخبرة.

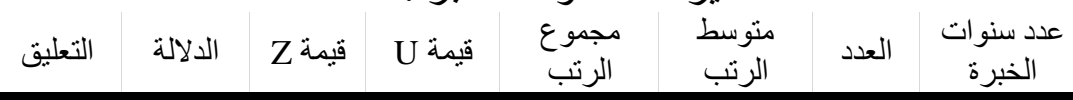

\begin{tabular}{|c|c|c|c|c|c|c|c|c|}
\hline \multirow{2}{*}{ غير دالة } & \multirow{2}{*}{0.290} & 1.058 & \multirow{2}{*}{300.5} & 391.50 & 30.12 & 13 & ما بين بـ & لمعوقات تطبيق الكبة \\
\hline & & & & 2093.50 & 36.73 & 57 & •ا اكتر منوات & \\
\hline
\end{tabular}

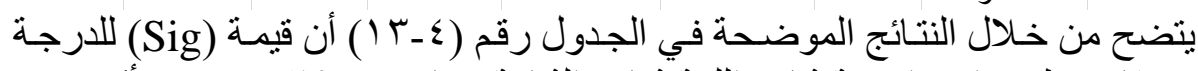

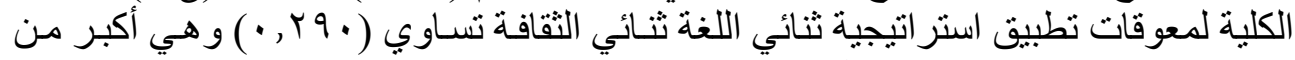

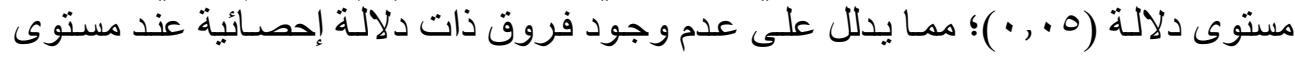

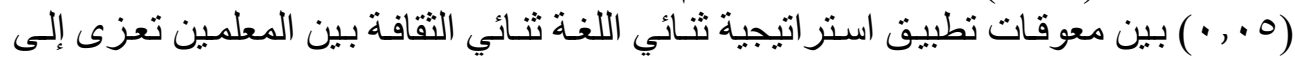

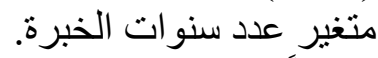

أجرى الباحثنان اختبار التوزيع الطبيعي Tests of Normality (اختبار - Shapiro

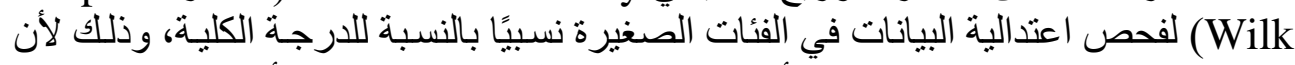

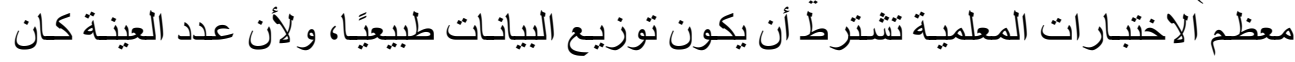

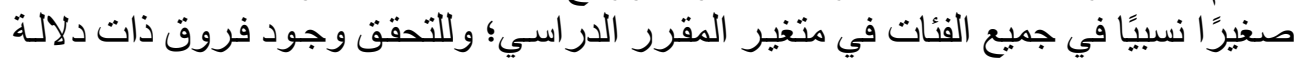

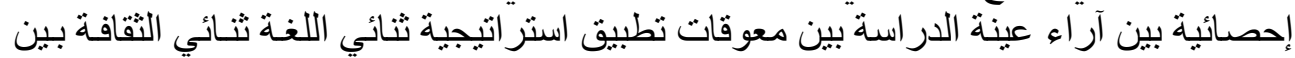

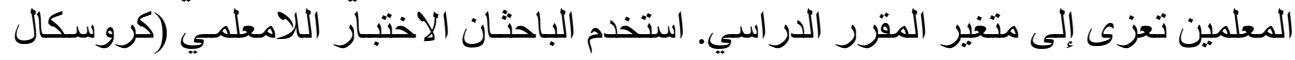

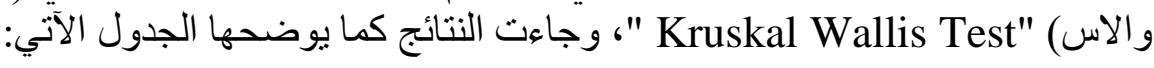


جدول رقم (ع ـ ـ ا): نتائج اختبار " Kruskal Wallis Test " للفروق بين استجابات

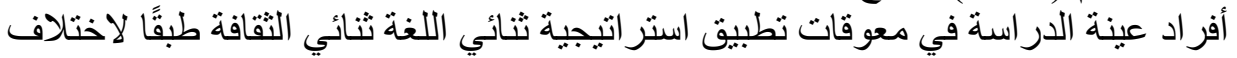
المقرر مانغير المقرر الدراسي.

\begin{tabular}{|c|c|c|c|c|c|c|}
\hline & & كاي & الرتب & & الدر اسي & \\
\hline \multirow{11}{*}{ غالة } & \multirow{11}{*}{$\cdot, r \cdot \Lambda$} & \multirow{11}{*}{ Ir,Yqr } & 34.43 & 15 & عربي & \multirow{11}{*}{ تطبيق استر اتيجية الكلية لمعو قائي } \\
\hline & & & 40.23 & 13 & دين & \\
\hline & & & 16.50 & 7 & اجتماعيات & \\
\hline & & & 40.00 & 8 & علوم & \\
\hline & & & 39.86 & 11 & رياضيات & \\
\hline & & & 31.10 & 5 & إنجليزي & \\
\hline & & & 47.63 & 4 & حاسب & \\
\hline & & & 13.00 & 1 & تربية بدنية & \\
\hline & & & 17.00 & 1 & تربية فنية & \\
\hline & & & 15.50 & 1 & نطق & \\
\hline & & & 45.00 & 4 & أخرى & \\
\hline
\end{tabular}

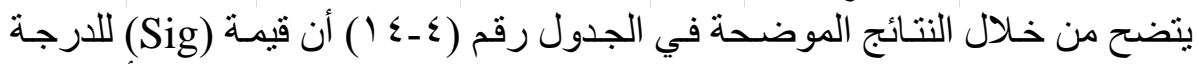

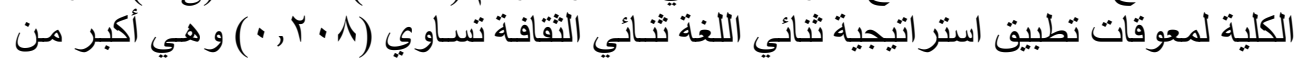

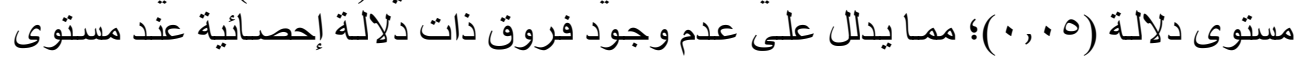

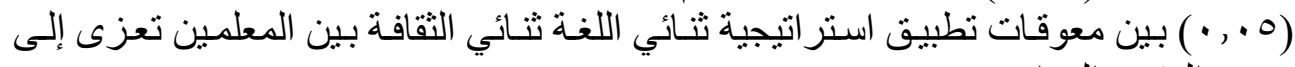
متغير المقرر الدراسي. التوصيات

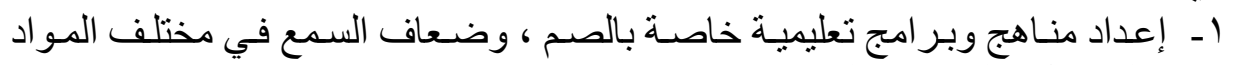

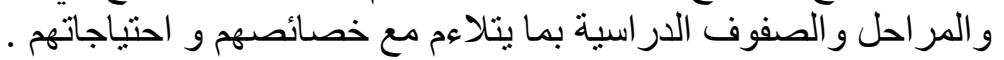

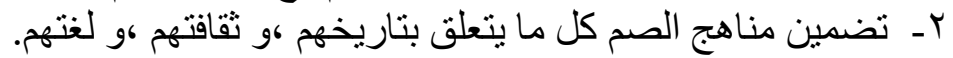

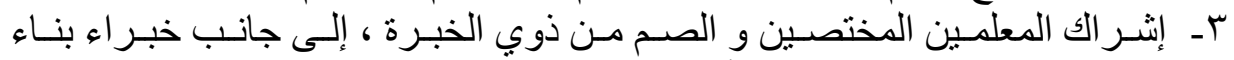

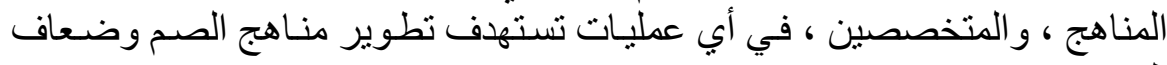

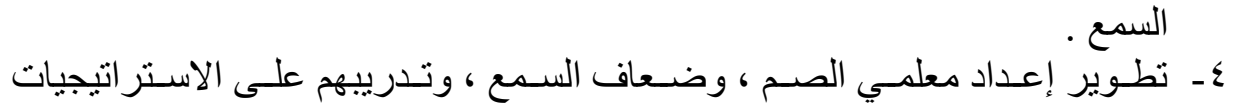

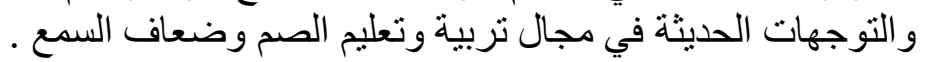

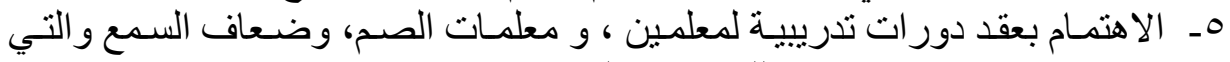
تختص باستر اتيجيات ثنائي اللغة ثنائي الثقافة . 


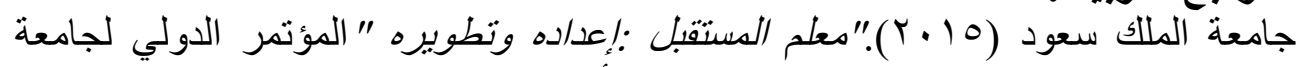

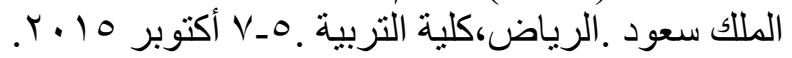

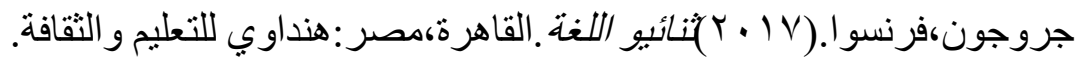

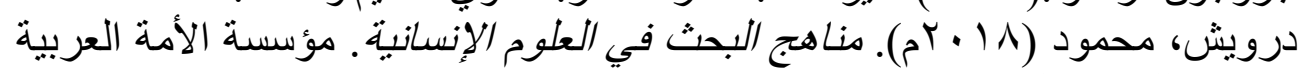

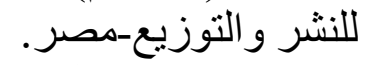
رسلانهاهين(9 . .ب.بيكولوجية العاقات العقلية والحسية.القاهرة،مصر:مكتبة الأنجلو المصرية.

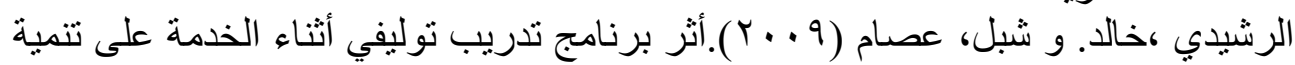

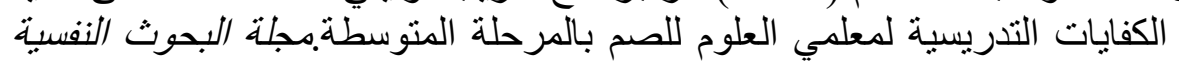

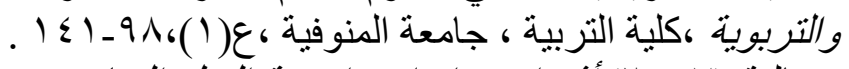

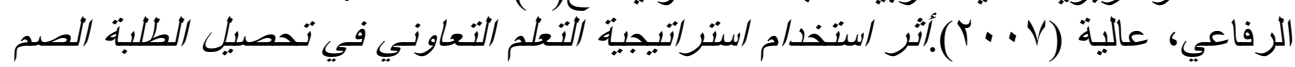

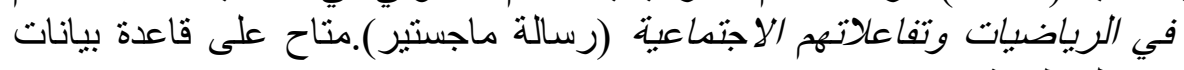

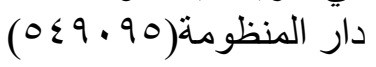

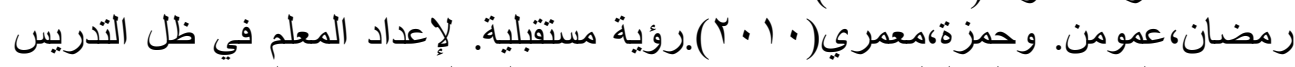

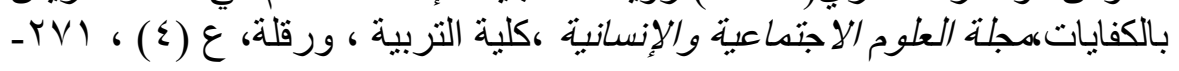
بر بالكفايت

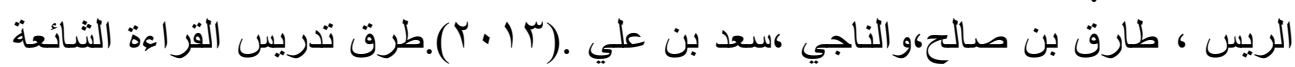

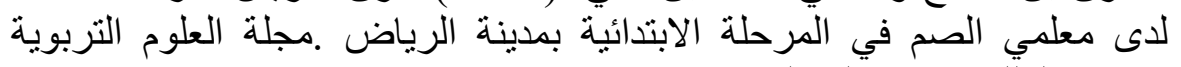

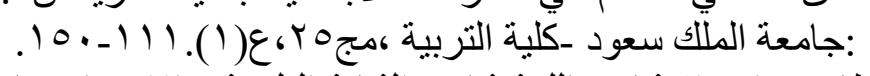

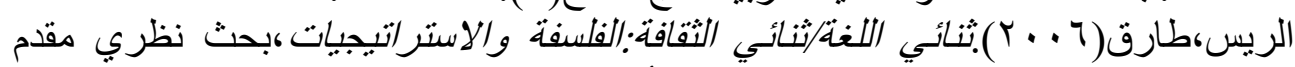

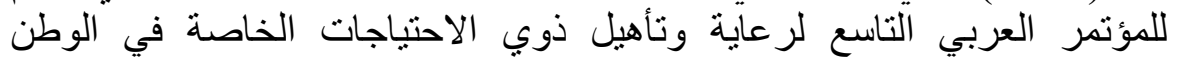

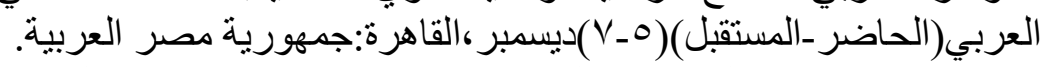

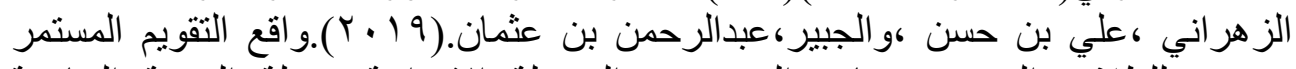

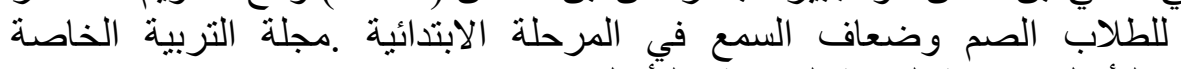

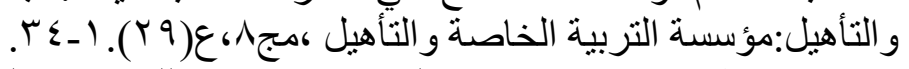

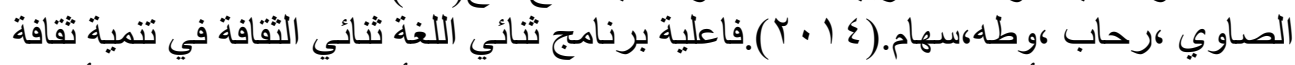

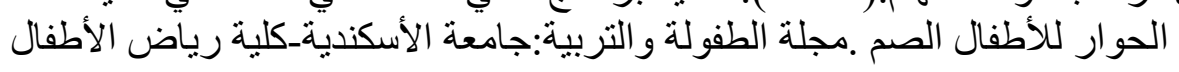

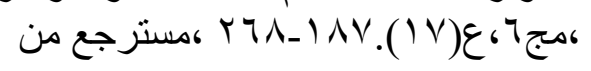
http://search.mandumah.com/Record/666824. 


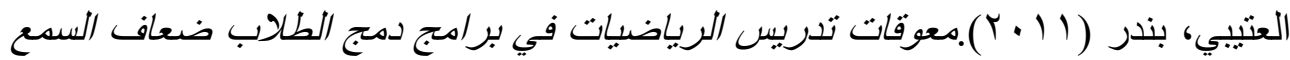

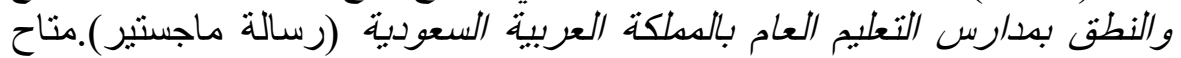

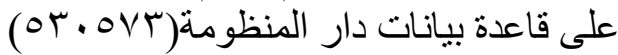

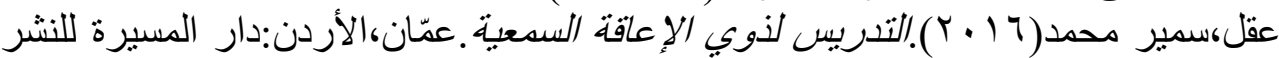
و التوزيع. مينان.

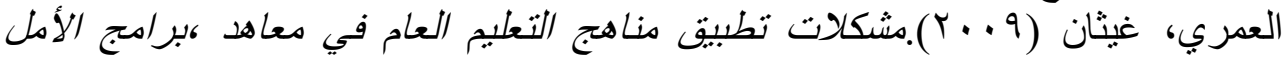

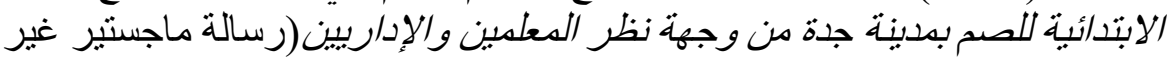

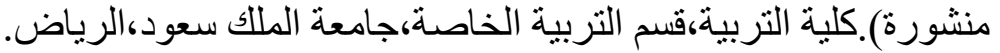

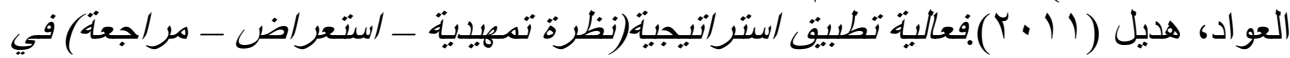

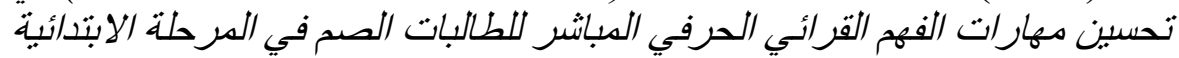

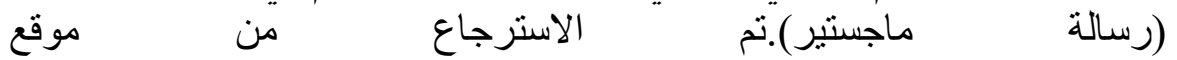

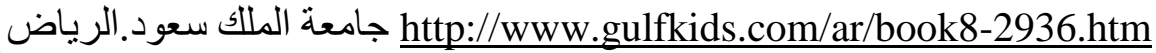

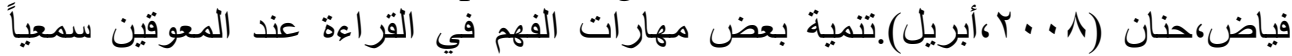

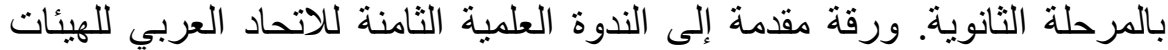

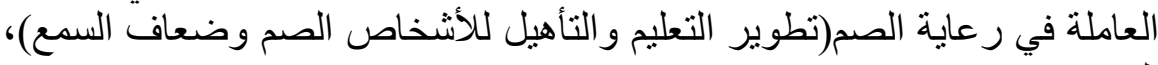

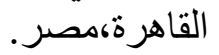

قابيل، نهاد (10 ـ ب)فاعلية تطبيق استراتيجية (الفصل مابين لغة الإشارة و اللغة العربية)

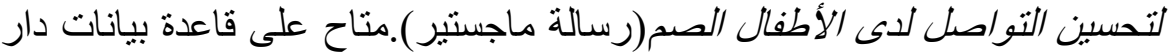

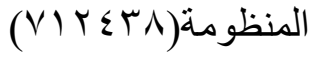

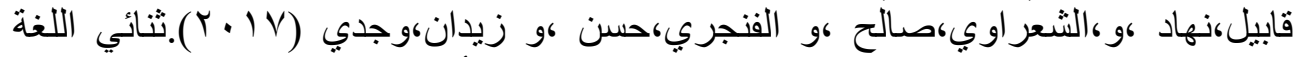

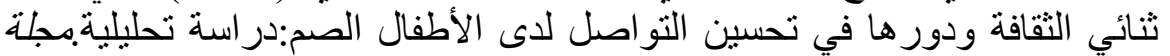

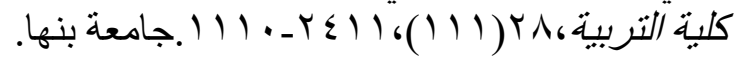

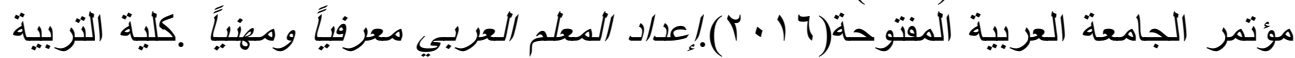

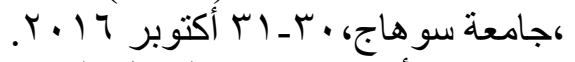

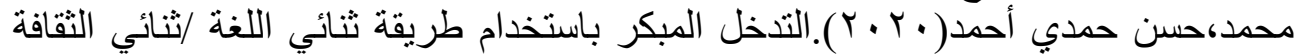

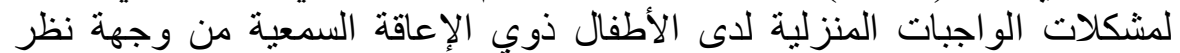

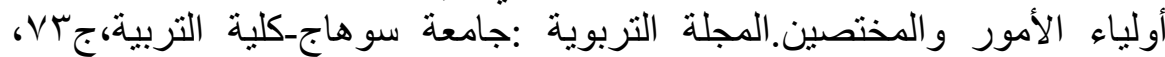

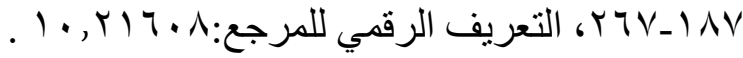

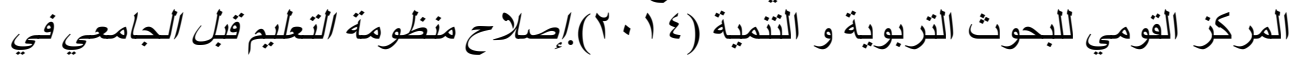

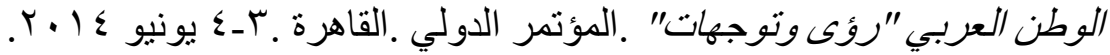




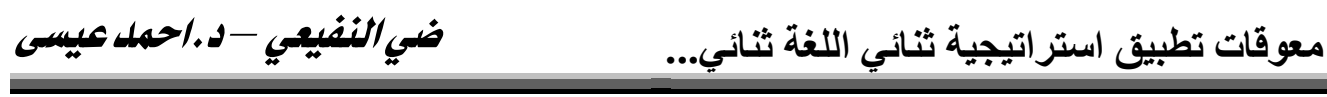

مصطفى، فتحي(0 ( ) ). الكفايات المهنية لمعلمي الطلاب الصم وضعاف السمع في ضوء

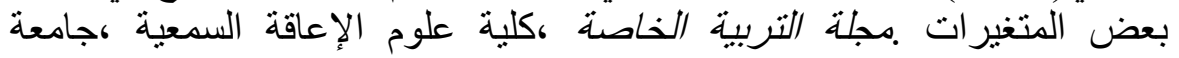

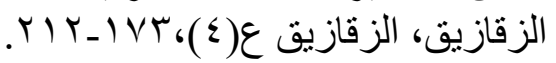

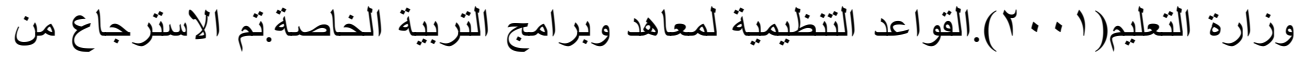
https://departments.moe.gov.sa/SPED/Documents/serules.pdf يوسف، ماهر إسماعيل صبري محمد(و . . (Y).المدخل للمناهج وطرق التدربيس.تم

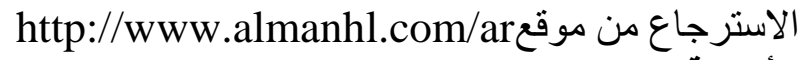

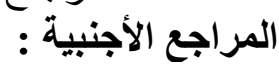

Beena, A., Haritha, S., \& Arun, S. (2021). Bimodal bilingualism: Acquisition of english as a second language among deaf primary school children. Annals of the Romanian Society for Cell Biology, 25(5), 52135223. Retrieved from https://www.proquest.com/scholarlyjournals/bimodal-bilingualism-acquisition-englishas/docview/2564189415/se-2?accountid=142908

Bees,F\&Humes,L(2008).Audiology:The

Fundamentals.Baltimore:Lippincott Williams \&Wilkins.

Dammeyer , Jasper (2014). Literacy Skills among Deaf and Hard of Hearing Students and Students with Cochlear Implants in Bilingual/Bicultural Education. Deafness \& Education International, Vol16No2,P108-119, DOI: 10.1179/1557069X13Y.0000000030.

Desmet, Timothy, \& Duyck, W. (2007). Bilingual language processing. LANGUAGE AND LINGUISTICS COMPASS, 1(3), 168194. Retrieved from http://hdl.handle.net/1854/LU-2115507

Durand, Sarah Rebecca (2008). Deaf identity, career-related self-efficacy, and perception of career barriers of deaf and hard-of-hearing individuals.Doctor of Philosophy.Fordham University.Education. The Volta Revieo, 110(2). 117-128.

Geeslin,Joseph David, I.,II. (2007). Deaf bilingual education: A comparison of the academic performance of deaf children of deaf parents and deaf children of hearing parents (Order No. 3287372). Available from ProQuest Central. (304856651). Retrieved from https://search-proquestcom.sdl.idm.oclc.org/docview/304856651 ?accountid=142908

Gough, J. M. (2014). Educators' perspectives on american sign language and english bilingual education for EC-12 deaf students (Order No. 3671021). Available from ProQuest Central. (1651182965). Retrieved 
from

https://search-proquest-

com.sdl.idm.oclc.org/docview/1651182965? accountid=142908

Hall, W.C., Smith, S.R., Sutter, E.J., DeWindt, L.A., \& Dye, T.D. (2018).

Considering parental hearing status as a social determinant of deaf population health: Insights from experiences of the "dinner table syndrome". PLoS ONE, 13.

Hallhan,Daniel P\&Kuffman,James M(2006).Exceptional Children : An Introduction to Special education.Bosten:Allyn and Bacon.

Hermans, D., Knoors, H., Ormel, E., \& Verhoeven, L. (2008). The relationship between the reading and signing skills of deaf children in bilingual education programs. Journal of Deaf Studies and Deaf Education $13(4)$

518-30. doi:http://dx.doi.org.sdl.idm.oclc.org/10.1093/deafed/enn009

Hrastinski, Iva \& Wilbur, Ronnie B.(2016). Academic Achievement of Deaf and Hard-of-Hearing Students in an ASL/English Bilingual Program. The Journal of Deaf Studies and Deaf Education, Vol21, No2,p156-170, https://doi.org/10.1093/deafed/env072.

Jambor, E. E. (2009). Quality of life of deaf and hard of hearing individuals in northern nevada (Order No. 3355585). Available from ProQuest Dissertations \& Theses Global. (304947759). Retrieved from https://search-proquest-com.sdl.idm.oclc.org/dissertationstheses/quality-life-deaf-hard-hearingindividuals/docview/304947759/se-2?accountid=142908

Johnson, Viola E.(2010).A phenomenological analysis of the perception of employability of the deaf and hard of hearing individuals following high school graduation .Doctor of Education.Union Institute \& University.

Krausnekera, Verena \& Beckerb, Claudia \& Audeoudc, Mireille \& Tarcsiovád, Darina(2020). Bilingual school education with spoken and signed languages in Europe. International Journal of Bilingual Education and Bilingualism,p1-17, DOI: 10.1080/13670050.2020.1799325.

Lenihan, S. (2010). Trend and Challenges in Teacher Preperation in Deaf .

Li, Ying. (2005). The effects of the bilingual strategy-preview-viewreview - on the comprehension of science concepts by deaf 
ASL/English and hearing mexican-american spanish /English bilingual students (Order No. 3194851). Available from ProQuest Dissertations \& Theses Global. (305381982). Retrieved from https://www.proquest.com/dissertations-theses/effects-bilingualstrategy-preview-view-review-on/docview/305381982/se2? accountid $=142908$

Marschark, M. (2001). Language development in children who are deaf: A research synthesis., 1-72. Retrieved from https://search-proquestcom.sdl.idm.oclc.org/scholarly-journals/language-developmentchildren-who-are-deaf/docview/62255397/se-2? accountid=142908

Paul,Peter V\&Moores,Donald F(2012).Deat Epistemologies Multiple Perspectives on The Acquisition of Knowledge.Washington,Dc:Gallaudet University press.

Sibanda, Patrick \& Tlale,Lloyed (2019). CHALLENGES EXPERIENCED IN THE PRACTICE OF SIGN BILINGUAL EDUCATION AS A STRATEGY FOR INCLUSION OF DEAF CHILDREN IN MAINSTREAM SCHOOLS IN ZIMBABWE.Journal of social science and humanities, vol16 NO1,p1-12.

Tej,B \& William,R.(2006).Bilingualism and Second Language Acquisition ,Blackwell Publishing LTD. 